\title{
Missing Stratospheric Ozone Decrease at Southern Hemisphere Middle Latitudes after Mt. Pinatubo: A Dynamical Perspective
}

\author{
C. SCHNADT POBERAJ* AND J. STAEHELIN \\ Institute for Atmospheric and Climate Science, ETH Zurich, Zurich, Switzerland \\ D. BRUNNER \\ Empa Swiss Federal Laboratories for Materials Science and Technology, Dübendorf, Switzerland
}

(Manuscript received 2 December 2010, in final form 1 April 2011)

\begin{abstract}
Although large total ozone decreases occurred in the Northern Hemisphere extratropics in the years after the volcanic eruption of Mt. Pinatubo that are generally attributed to the eruption, comparable decreases did not emerge in the Southern Hemisphere. To study this missing decrease, a multiple linear regression was applied to the Chemical and Dynamical Influences on Decadal Ozone Change (CANDIDOZ) Assimilated Three-Dimensional Ozone (CATO) dataset including the solar cycle, the quasi-biennial oscillation (QBO), the effect of volcanic eruptions, the lower stratospheric (LS) Eliassen-Palm (EP) flux to describe the BrewerDobson circulation, and stratospheric chlorine increase as explanatory variables. Volcanically induced chemical ozone depletion was overcompensated by the QBO and by a pronounced EP flux anomaly. Using NCEP-NCAR reanalysis data, it is found that the anomalous EP flux was caused by several significant stratospheric wave events (SWEs) from September-November 1991 through 1992 that, together with aerosol heating, led to a significantly enhanced Brewer-Dobson circulation and more ozone transport from the tropics to the extratropics. The onset of the volcanic ozone loss was shifted into 1992 and the strength of the signal was reduced. Most SWEs can be traced back to the troposphere and a significant fraction was associated with atmospheric blocking patterns preceding the SWEs. In 1991/92, the southern annular mode was in a negative phase and El Niño-Southern Oscillation in a warm phase. It is suggested that this constellation favored a flow preconditioning toward quasi-stationary features including blocking, which was significantly enhanced in 1991/92. During June-August 1992, blocking occurred preferably over the southeastern Pacific, pointing to a major ENSO influence on LS wave activity.
\end{abstract}

\section{Introduction}

The volcanic eruption of Mount Pinatubo in June 1991 produced a global increase in stratospheric aerosol loading that persisted for several years (e.g., Thomason and Peter 2006) and significantly disturbed stratospheric chemistry and dynamics (WMO 2003). The volcanic aerosol had two main impacts: the incoming solar radiation was scattered back to space, cooling the earth's

\footnotetext{
* Current affiliation: Empa Swiss Federal Laboratories for Materials Science and Technology, Dübendorf, Switzerland.
}

Corresponding author address: Dr. C. Schnadt Poberaj, Empa Swiss Federal Laboratories for Materials Science and Technology, Dübendorf, Switzerland.

E-mail: christina.schnadt@empa.ch surface (Dutton and Christy 1992; Minnis et al. 1993), and infrared absorption led to significant heating of the tropical lower stratosphere (LS) (Labitzke and McCormick 1992). The second main impact concerned heterogeneous chemical reactions on the volcanic aerosol, which lead to suppression of $\mathrm{NO}_{x}$ and consequently to enhanced catalytic ozone destruction by chlorine radicals (Solomon 1999). Pronounced stratospheric $\mathrm{NO}_{2}$ depletions were observed at Northern Hemisphere (NH) and Southern Hemisphere (SH) midlatitudes in 1992/93 (WMO 2007), indicating heterogeneous processing on the aerosol surfaces. However, while large ozone decreases were observed in the $\mathrm{NH}$ extratropics for several years following the eruption (e.g., Kerr et al. 1993; Hofmann et al. 1994; Gleason et al. 1993; Randel et al. 1995), no comparable ozone decrease was seen at $\mathrm{SH}$ midlatitudes (WMO 2003). In contrast, a positive total ozone anomaly

DOI: 10.1175/JAS-D-10-05004.1 

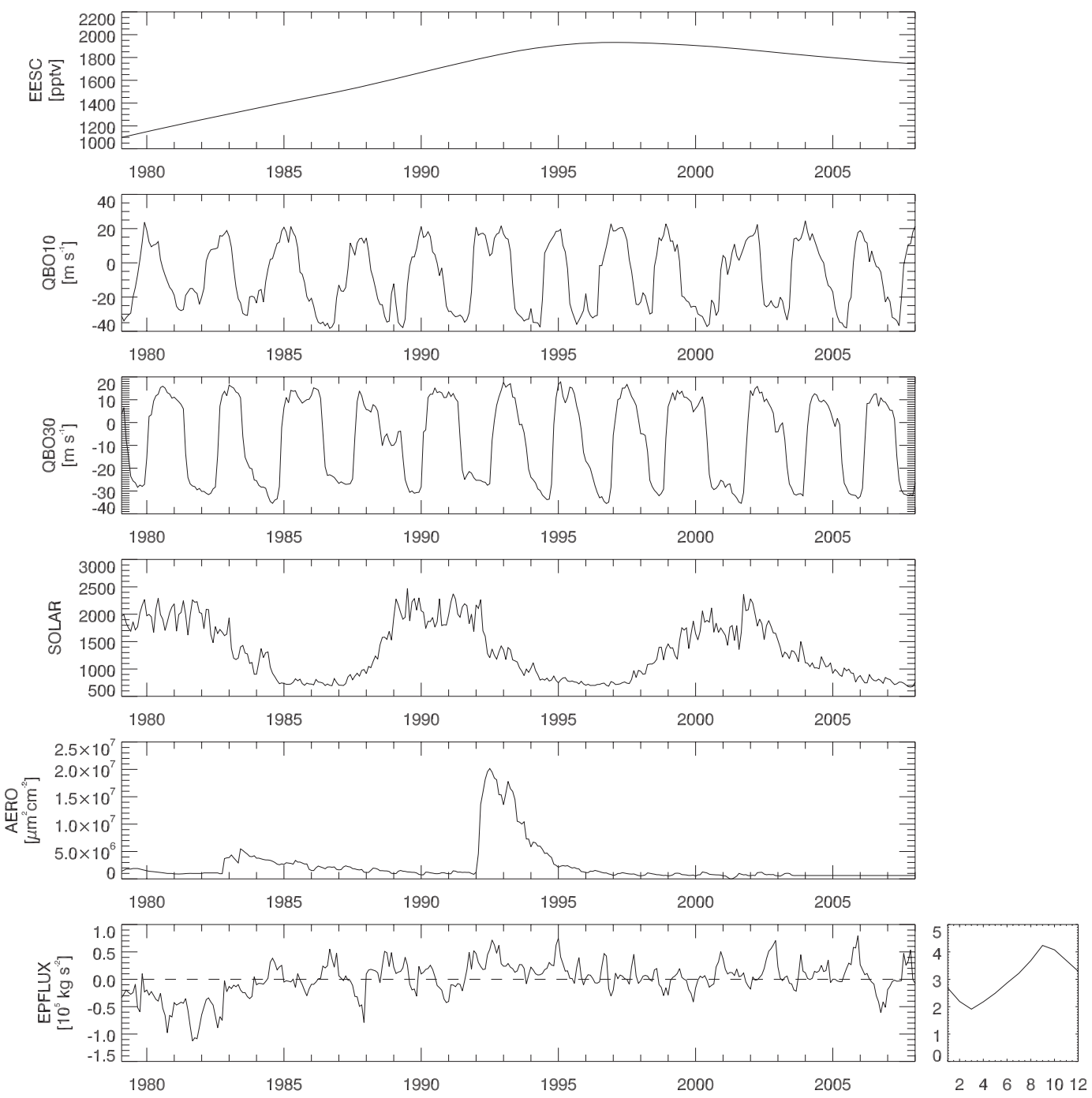

FIG. 1. Time series of monthly proxy data from January 1979 to December 2007: EESC (pptv), QBO10 and QBO30 $\left(\mathrm{m} \mathrm{s}^{-1}\right)$, SOLAR (Mg II core-to-wing ratio), AERO $\left(\mu \mathrm{m}^{2} \mathrm{~cm}^{-2}\right)$, and EP flux $\left(10^{5} \mathrm{~kg} \mathrm{~s}^{-2}\right)$ (see Table 1 for proxy explanations). Tick marks indicate January of each year. For the EP flux proxy, the deseasonalized data are shown. The mean seasonal cycle is additionally displayed in a small panel to the right.

appeared between the middle of 1991 and the middle of 1992 (Randel and Wu 1996; see also our Fig. 4). Several studies (Stolarski et al. 2006; Fleming et al. 2007; Telford et al. 2009) speculated that the lack of the SH midlatitude Pinatubo signal was caused by interannual dynamical variability masking the chemical effect. However, the studies did not further investigate the explicit dynamical causes or processes that led to the compensation of the chemical signal.

The main potentially responsible dynamical processes, alone or in combination, are the quasi-biennial oscillation (QBO) and the Brewer-Dobson circulation, which may have been altered by the aerosol radiative heating and/or an enhanced upward flux of planetary wave activity from the troposphere.
The QBO is a downward-propagating variation of easterly and westerly winds with a variable period of about 28 months caused by vertically propagating equatorial waves (e.g., Baldwin et al. 2001). The QBO forcing induces a direct meridional circulation at low to midlatitudes (e.g., Kinnersley and Tung 1999) and is responsible for the so-called ozone QBO: in the tropics, positive (negative) column ozone anomalies occur during the westerly (easterly) phase (Randel and Wu 1996). In the extratropics, mass continuity requires a return arm to the QBO circulation. There, total ozone anomalies of the opposite sign as in the tropics occur (Randel and Wu 1996). In 1991, the QBO was in its easterly phase (Fig. 1). In 1992, westerly winds appeared at $30 \mathrm{~km}$, reaching the LS in the middle of the year. Comparing 
satellite-derived total ozone anomalies of 1979-94 with their QBO components, Randel and Wu (1996) elucidate that the positive SH extratropical anomaly in 1991/92 was partly caused by the QBO, primarily in the second half of 1991. However, these results also show that the QBO alone cannot explain the observed anomaly. Hence, other dynamical processes must be considered to explain its remaining part.

The volcanic aerosol cloud itself significantly affected atmospheric dynamics through its impact on stratospheric temperatures (e.g., Stenchikov et al. 2002; Pitari and Mancini 2002; Graf et al. 2007; and many others). For instance, Pitari and Mancini (2002) using a coupled chemistry-climate model showed that the modeled Brewer-Dobson circulation was altered by aerosol radiative heating in the first year after the eruption, and enhanced extratropical downwelling in both hemispheres moved more ozone down toward the extratropical tropopause. This dynamical ozone supply counteracted the volcanically induced chemical ozone decrease during 1992 such that the largest impact of the Pinatubo aerosols was postponed until 1993.

Another key process is planetary wave activity emanating from the troposphere that drives the BrewerDobson circulation and hence influences stratospheric ozone on the global scale (Fusco and Salby 1999; Randel et al. 2002). For NH winters impacted by the major volcanic eruptions of Agung in 1963, El Chichón in 1982, and Mt. Pinatubo in 1991, much more planetary wave energy than in nonvolcanic winters occurred in the troposphere and propagated into the stratosphere (Graf et al. 2007). Indeed, after the Pinatubo eruption a positive anomaly in LS vertical planetary wave propagation was observed not only during the NH 1991/92 winter (Brunner et al. 2006b, their Fig. 2), where the polar stratosphere was significantly disturbed (see our Fig. 6; Rosier et al. 1994; Rosier and Lawrence 1999), but also at SH midlatitudes in 1991/92 (Brunner et al. 2006b), indicating an anomaly of the Brewer-Dobson circulation possibly important for understanding the lack of the SH Pinatubo signal.

An enhanced upward flux of planetary wave activity in the SH may be related to the southern annular mode (SAM), the leading mode of the SH extratropical circulation variability (e.g., Thompson and Wallace 2000). The SAM is coupled to the LS circulation when the zonal flow velocity is below a certain threshold to allow wave-mean flow interaction (Charney and Drazin 1961). This condition is mostly confined to austral spring (Thompson and Wallace 2000; Thompson et al. 2005). While wave-mean flow interaction is usually small in the SH winter (Thompson and Wallace 2000), there are a few notable exceptions. In 1997, the stratospheric polar vortex was repeatedly disturbed by waves propagating upward from tropospheric quasi-stationary anomalies including blocking highs (Nishii and Nakamura 2004). In 2002, several wave events originating from the midlatitude troposphere disturbed the winter polar vortex (Newman and Nash 2005), which finally resulted in the prominent split of the Antarctic ozone hole (Varotsos 2002).

Finally, ENSO warm phases, which also occurred in the post-Pinatubo, post-Agung, and post-El Chichón periods (e.g., Turner 2004), have been documented to be characterized by stronger upward propagation of quasi-stationary waves in the upper troposphere and stratosphere during all seasons except austral summer compared to the cold phase (Rao et al. 2004). In the troposphere, the ENSO warm phase is associated with an enhanced atmospheric blocking frequency over the southeastern Pacific (Renwick 1998; Renwick and Revell 1999). Blocking is a synoptic condition in which the prevailing westerlies are diverted to the north and south so that easterlies occur for several days on a spatial scale larger than the synoptic scale (Rex 1950). Blocking weather systems in the $\mathrm{NH}$ and $\mathrm{SH}$ are relevant to stratospheric variability because they modify preexisting tropospheric stationary planetary waves such that upward propagation into the stratosphere may result (Martius et al. 2009; Woollings et al. 2010). Hence, increased blocking during ENSO warm phases may explain the increased upward wave propagation observed by Rao et al. (2004).

In this contribution we investigate the causes for the missing SH column ozone decrease following the Pinatubo eruption. Section 2 describes the data sources, and section 3 presents the methodology. In section $4 a$, using multiple linear regression, the relative roles of the most important factors affecting SH midlatitude column ozone are investigated. We will show that, in addition to a QBO contribution, the absent SH ozone decrease can largely be assigned to a LS planetary wave activity anomaly. In section $4 \mathrm{~b}$, we present evidence that this planetary wave activity significantly contributed to an increase of the Brewer-Dobson circulation in the first year after the eruption. Section $4 \mathrm{c}$ elucidates the tropospherestratosphere connection of wave activity. Finally, the relationship between individual LS wave events and blocking episodes preceding these events is discussed in section 4d. Additionally, the relationships among wave activity, blocking frequency, and SAM and ENSO are addressed. Section 5 contains concluding remarks.

\section{Data}

The Chemical and Dynamical Influences on Decadal Ozone Change (CANDIDOZ) Assimilated ThreeDimensional Ozone (CATO) dataset is a statistically 
TABLE 1. Datasets used in the study. SOLAR, QBO, and AERO proxies as in Brunner et al. (2006b).

\begin{tabular}{|c|c|c|}
\hline Name & Description & Source \\
\hline SOLAR & Proxy. MG II index (core-to-wing ratio) & http://www.iup.physik.uni-bremen.de/gome/gomemgii.html \\
\hline QBO10 & Proxy. QBO at $10 \mathrm{hPa}$ measured at Singapore & Courtesy of B. Naujokat (FU Berlin) \\
\hline QBO30 & Proxy. QBO at $30 \mathrm{hPa}$ measured at Singapore & Courtesy of B. Naujokat (FU Berlin) \\
\hline AERO & $\begin{array}{l}\text { Proxy. Volcanic aerosols, vertically integrated } \\
\text { aerosol surface area per unit surface }\end{array}$ & $\begin{array}{l}\text { SPARC Stratospheric Aerosol Assessment } \\
\text { (http://www-sparc.larc.nasa.gov) }\end{array}$ \\
\hline EESC & Proxy. Equivalent effective stratospheric chlorine & $\begin{array}{l}\text { Goddard automailer (http://acdb-ext.gsfc.nasa.gov/Data_services/ } \\
\text { automailer/) }\end{array}$ \\
\hline SBUV & $\begin{array}{l}\text { Solar backscatter ultraviolet radiometer } \\
\quad(\text { SBUV/SBUV/2) monthly and zonal mean profile } \\
\text { ozone dataset (version } 8 \text {, revision } 0)\end{array}$ & http://acdb-ext.gsfc.nasa.gov/Data_services/merged/index.html \\
\hline$F_{z}$ & $\begin{array}{l}\text { Proxy. Vertical component of EP flux at } 100 \mathrm{hPa} \\
\text { averaged over } 45^{\circ}-75^{\circ} \mathrm{S}\end{array}$ & $\begin{array}{l}\text { NNR data processed by the Alfred Wegener Institute (AWI) } \\
\text { Potsdam (http://www.awi.de/en/research/rsearch_divisions/ } \\
\text { climate_science/atmospheric_circulations/projects/candidoz/ } \\
\text { ep_flux_data/) }\end{array}$ \\
\hline SAM & Index of the southern annular mode. Used in Fig. 10. & $\begin{array}{l}\text { Climate Prediction Center (CPC) of the National Oceanic } \\
\text { and Atmospheric Administration (NOAA) } \\
\text { (http://www.cpc.ncep.noaa.gov/products/precip/CWlink/ } \\
\text { daily_ao_index/aao/aao.shtml) }\end{array}$ \\
\hline SOI & Index of the Southern Oscillation. Used in Fig. 10. & $\begin{array}{l}\text { Australian Bureau of Meteorology (ftp://ftp.bom.gov.au/anon/ } \\
\text { home/ncc/www/sco/soi/soiplaintext.html) }\end{array}$ \\
\hline
\end{tabular}

reconstructed ozone dataset describing its spatial distribution in the stratosphere in equivalent latitude (EL)potential temperature coordinates on a quasi-global scale and providing the horizontal distribution of residual ozone columns in the troposphere. CATO has been derived by combining National Institute of Water and Atmospheric Research (NIWA; New Zealand) assimilated satellite total ozone (Bodeker et al. 2001, 2005) with meteorological information [analysis or reanalysis data from the European Centre for Medium-Range Weather Forecasts (ECMWF)] on short-term meridional air mass excursions due to isentropic transport in a data assimilation approach (Brunner et al. 2006a). In the version used, the dataset above about $30-\mathrm{km}$ altitude has been relaxed toward the monthly mean climatology of Fortuin and Kelder (1998), as the reconstruction fails to produce a realistic distribution because of the short chemical lifetime of ozone at these altitudes. Any variability in the assimilated total ozone is therefore assigned to variations in the LS while upper stratospheric (US) variability is damped. The CATO dataset currently covers the period 1979-2007. In this study, CATO total ozone, area averaged over $\mathrm{SH}$ midlatitudes $\left(42^{\circ}-60^{\circ} \mathrm{S} \mathrm{EL}\right)$, is used.

For the analysis of dynamical processes in section 4, we employ the global observational dataset from the National Centers for Environmental Prediction (NCEP)National Center for Atmospheric Research (NCAR) reanalysis (NNR; Kalnay et al. 1996). The dataset contains daily averaged geopotential height, horizontal wind, and temperature fields on a $2.5^{\circ} \times 2.5^{\circ}$ grid at 17 vertical pressure levels extending from 1000 to $10 \mathrm{hPa}$.

\section{Analysis}

\section{a. Regression model}

A multiple linear regression analysis has been applied to CATO for the four seasons separately:

$$
Y_{t}=a+b \operatorname{EESC}(t)+\sum^{N} c_{j} X_{j}(t)+\varepsilon(t),
$$

where $t$ is the time index representing three-monthly or annual means since the start of record, $Y_{t}$ is the threemonthly or annual mean total ozone, $a$ is the intercept of ozone time series, $b$ is the equivalent effective stratospheric chlorine (EESC) coefficient, $c_{j} X_{j}(t)$ is the time series of other explanatory $X_{j}$ variables $(j=1, N)$ and their coefficients $c_{j}$, and $\varepsilon(t)$ is residual variations not described by the model.

Dynamical variability is accounted for in two ways: in the EL-potential temperature coordinate system employed by CATO, variability by LS planetary waves and associated reversible meridional transport, which largely affects total ozone in geographical coordinates, is mostly eliminated (Wohltmann et al. 2007). Additionally, the strength of the Brewer-Dobson circulation is accounted for by using the vertical component of the EliassenPalm (EP) flux $F_{z}$ as a proxy (see below).

Because in CATO US variability is damped, the regression model was applied to the LS column only. This was achieved by subtracting a US column, derived from solar backscatter ultraviolet radiometer (SBUV) satellite data (Table 1; see also Bhartia et al. 2004), from the total CATO column. Furthermore, a separate, simple 
TABLE 2. Cross correlations between explanatory variables. Important correlations discussed in the text are in boldface.

\begin{tabular}{|c|c|c|c|c|c|c|c|c|c|c|c|c|c|}
\hline \multicolumn{7}{|c|}{ DJF } & \multicolumn{7}{|c|}{ MAM } \\
\hline & SOLAR & QBO10 & QBO30 & AERO & EPFLUX & VPSC & & SOLAR & QBO10 & QBO30 & AERO & EPFLUX & VPSC \\
\hline EESC & -0.28 & 0.14 & -0.005 & 0.04 & 0.82 & 0.74 & EESC & -0.33 & -0.001 & 0.01 & 0.10 & 0.76 & 0.75 \\
\hline VPSC & -0.28 & 0.19 & 0.12 & -0.13 & 0.52 & & VPSC & -0.28 & 0.04 & 0.16 & -0.12 & 0.49 & \\
\hline EPFLUX & -0.33 & 0.36 & -0.11 & 0.31 & & & EPFLUX & -0.23 & 0.13 & 0.09 & 0.36 & & \\
\hline AERO & -0.005 & 0.19 & 0.06 & & & & AERO & -0.04 & 0.14 & -0.09 & & & \\
\hline QBO30 & 0.02 & 0.1 & & & & & QBO30 & 0.05 & 0.32 & & & & \\
\hline \multirow[t]{3}{*}{ QBO10 } & 0.004 & & & & & & QBO10 & 0.01 & & & & & \\
\hline & & & JJA & & & & & & & SON & & & \\
\hline & SOLAR & QBO10 & QBO30 & AERO & EPFLUX & VPSC & & SOLAR & QBO10 & QBO30 & AERO & EPFLUX & VPSC \\
\hline EESC & -0.26 & 0.007 & 0.03 & 0.06 & 0.44 & 0.84 & EESC & -0.28 & -0.02 & -0.006 & 0.02 & 0.58 & 0.7 \\
\hline VPSC & -0.21 & 0.06 & -0.01 & -0.03 & 0.20 & & VPSC & -0.23 & 0.18 & -0.05 & -0.1 & 0.12 & \\
\hline EPFLUX & -0.34 & -0.05 & -0.11 & 0.42 & & & EPFLUX & -0.21 & 0.07 & -0.31 & 0.26 & & \\
\hline AERO & -0.14 & 0.05 & 0.03 & & & & AERO & -0.13 & 0.11 & 0.11 & & & \\
\hline QBO30 & -0.03 & -0.09 & & & & & QBO30 & -0.05 & -0.23 & & & & \\
\hline QBO10 & -0.16 & & & & & & QBO10 & 0.003 & & & & & \\
\hline
\end{tabular}

regression model was applied to the SBUV data to estimate the contributions of EESC and solar cycle variability on US ozone. In this way it was possible to quantify the US and LS contributions to EESC-related changes in total column ozone separately (Fig. 3; upper stratosphere and EESC, respectively). For the solar cycle, the US and LS contributions were added up since by far the largest contribution originated from the US (Fig. 3; solar cycle). Finally, to compare the regression results with CATO total ozone and to depict the contributions of individual processes on the long-term evolution (section 4a), the total column was reconstructed by adding the SBUV EESC and solar cycle terms back to the modeled LS column.

For the regression analysis, the different explanatory variables have been averaged to three-monthly means. Their sources are listed in Table 1; their original time series are shown in Fig. 1. For the QBO, two separate components are used, namely the zonal wind at 10 and $30 \mathrm{hPa}$ to be able to fit any possible phase lag between the QBO and total ozone. The 11-yr solar cycle influence is described by the Mg II solar index (Viereck et al. 2001), and the influence of the two major volcanic eruptions of El Chichón in 1982 and Mt. Pinatubo in 1991 by the hemispheric mean of the vertically integrated stratospheric aerosol surface area density compiled within the Stratospheric Processes and their Role in Climate (SPARC) stratospheric aerosol assessment framework (Thomason and Peter 2006). The anthropogenic influence through release of ozone-depleting substances (ODSs) is represented by EESC. The EESC series have been obtained from the Goddard automailer (Table 1). We use the definition given by the World Meteorological Organization (WMO) A1_2010A scenario in which the fractional release types are from Newman et al. (2006).
The mean age of air is set to $3.0 \mathrm{yr}$, the width of the age of air spectrum to $1.5 \mathrm{yr}$, and the bromine scaling factor to 60 . The Brewer-Dobson circulation is represented by $F_{z}$ averaged over $45^{\circ}-75^{\circ} \mathrm{S}$ in the lowermost stratosphere $(100 \mathrm{hPa})$. To account for the cumulative effects of $F_{z}$ on ozone several months later, the proxy was used in an accumulated form (Brunner et al. 2006b).

Although not a requirement, the explanatory variables in a multiple linear regression model should ideally be uncorrelated to allow for an unambiguous attribution of effects. However, strong correlations exist between EESC and $F_{z}$ during December-February (DJF) and March-May (MAM), and still notable ones during JuneAugust (JJA) and September-November (SON) (Table 2). The tight relationship suggests that the associated longterm change in midlatitude LS planetary wave activity (Fig. 2) may have been caused by ozone depletion (and greenhouse gas increases), as suggested by several modeling studies (e.g., Li et al. 2008, 2010; Oman et al. 2009; Polvani et al. 2011).

Additionally, EESC is also highly correlated with the accumulated volume of polar stratospheric clouds (VPSC) year-round (Table 2). In previous studies, VPSC was used as a proxy for polar ozone loss and its export from the polar region in spring (e.g., Brunner et al. 2006b) because it is highly correlated with chemical ozone loss in the NH (Rex et al. 2004). The high correlation between EESC and VPSC mainly arises from the 1980s before Antarctic chemical ozone losses became saturated during the 1990s, rendering ozone depletion less sensitive to VPSC (Tilmes et al. 2006).

To avoid collinearities, we have orthogonalized EESC and $F_{z}$ by subtracting a seasonally dependent EESC fit from $F_{z}$ (Fig. 2). Thus, any long-term ozone trend 

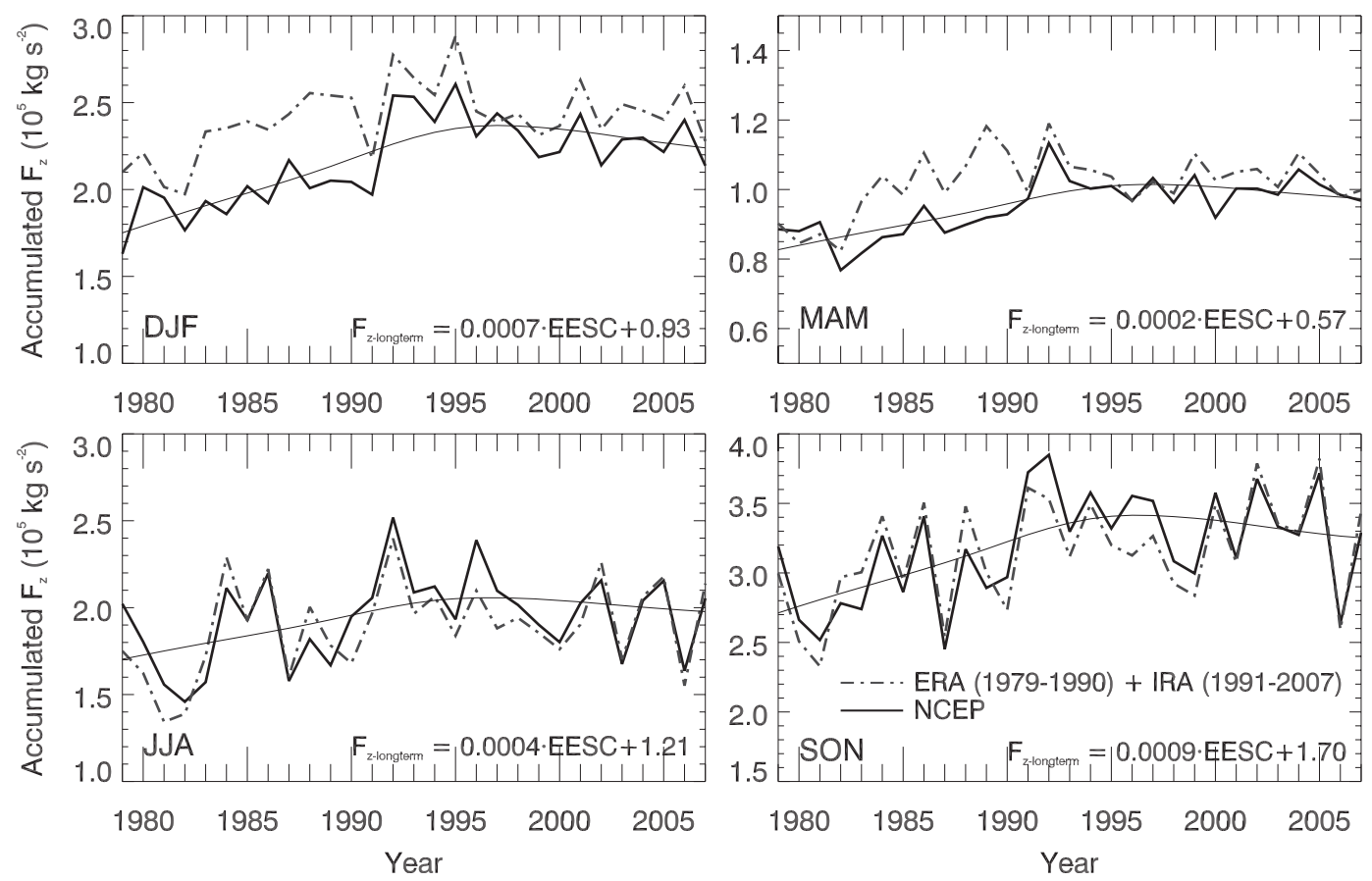

FIG. 2. Seasonal time series of the accumulated midlatitude $\left(45^{\circ}-75^{\circ} \mathrm{S}\right)$ EP flux $F_{z}\left(10^{5} \mathrm{~kg} \mathrm{~s}^{-2}\right)$ at $100 \mathrm{hPa}$, derived from NNR (black lines) and combined ERA-40 (1979-1990) and ERA-Interim (IRA) analyses (1991-2007) (gray lines). From top left to bottom right: DJF, MAM, JJA, and SON. In addition, the EESC fit of the NCEP $F_{z}$ series $F_{z \text {-longterm }}$ is displayed as thin black line for all seasons. The fitting equation is indicated at the bottom of each panel. Data courtesy of AWI (URL available in Table 1).

associated with changes in the Brewer-Dobson circulation is transferred to the EESC proxy, while $F_{z}$ is confined to describing interannual variations in wave activity. Additionally, VPSC is not used, and instead EESC is assumed to act as a proxy for both homogeneous midlatitude and heterogeneous polar ozone losses. Altogether, the net contribution of EESC to the modeled total ozone sum will be smaller than when describing chemical ozone loss alone (e.g., as in Brunner et al. 2006b) because of the canceling effects of chemical loss and dynamical supply.

One potential caveat of the regression analysis may lie in the use of $F_{z}$ as an explanatory variable, as it is based on reanalysis data. It has been argued that derived products from reanalyses are not suitable for trend estimates of the Brewer-Dobson circulation (Thompson and Solomon 2009). Indeed, there are considerable discrepancies in the vertical EP flux components for NNR and combined 40-yr ECMWF Re-Analysis (ERA-40) and ERA-Interim (hereafter IRA) analyses in the $\mathrm{SH}$, particularly in the 1980s during DJF and MAM (Fig. 2). However, while the magnitude of the upward EP flux trend differs in NNR and ERA-40/IRA, it is noticeable in both datasets, suggesting the effect is real. A strengthening of the Brewer-Dobson circulation over 1979-2001 has also been found in Japanese reanalyses (Iwasaki et al.
2009). Since NNR provide the only consistent dataset for 1979-2007, and using the combined ERA-40 and IRA $F_{z}$ data instead of NNR resulted in a reduced model performance, we performed the regression using the NNR flux, acknowledging the before-mentioned quantitative uncertainty. Additionally, as $F_{z}$ and the volcanic proxy are also mildly correlated (Table 2), indicating that the impact of volcanic eruptions on the Brewer-Dobson circulation is redundantly described, a clear quantitative attribution of these processes cannot be achieved. Thus, we will confine the discussion on the causes of the lack of a SH Pinatubo total ozone signal in section 4a to qualitative arguments. The difficulties of collinearity are much more severe in the $\mathrm{SH}$ datasets as compared to the NH. This also likely explains problems in detecting a Pinatubo signal in $\mathrm{SH}$ ozone in other statistical studies (e.g., Stolarski et al. 2006) and is possibly responsible for a failure of the analysis during MAM, where the volcanic proxy is assigned a positive but not statistically significant regression coefficient, yielding an ozone increase (Fig. 3b).

\section{b. Dynamical quantities}

The Brewer-Dobson circulation is characterized by tropical upwelling, poleward flow, and extratropical downwelling (e.g., Shepherd 2007). The bulk of this 
a) DJF

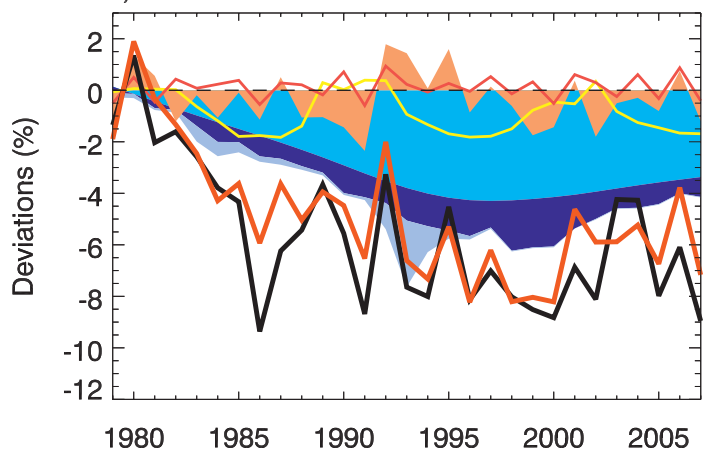

c) JJA

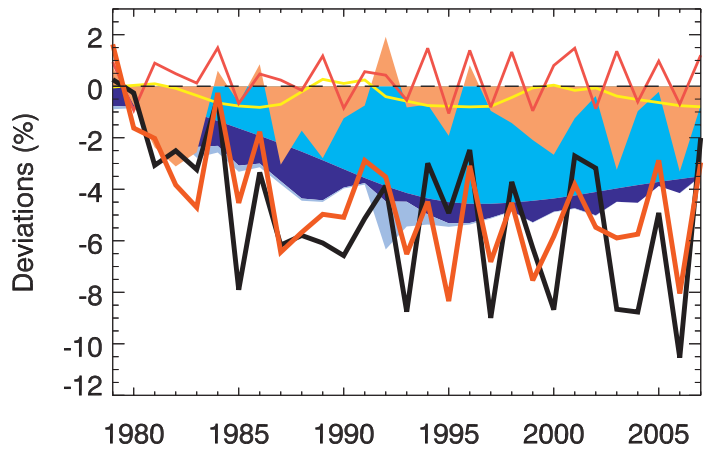

e) annual

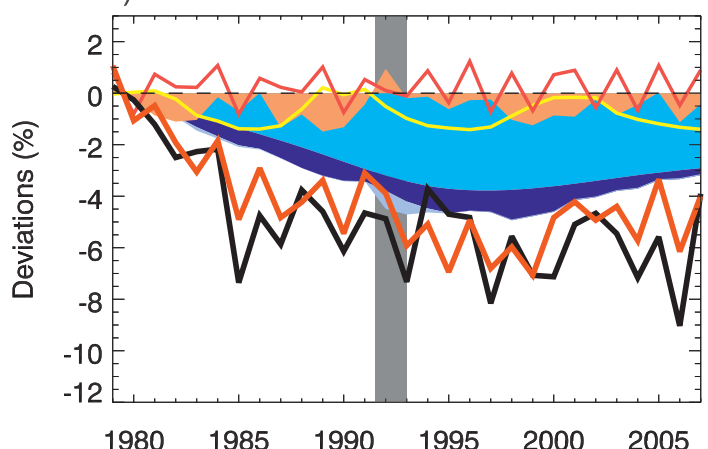

b) MAM

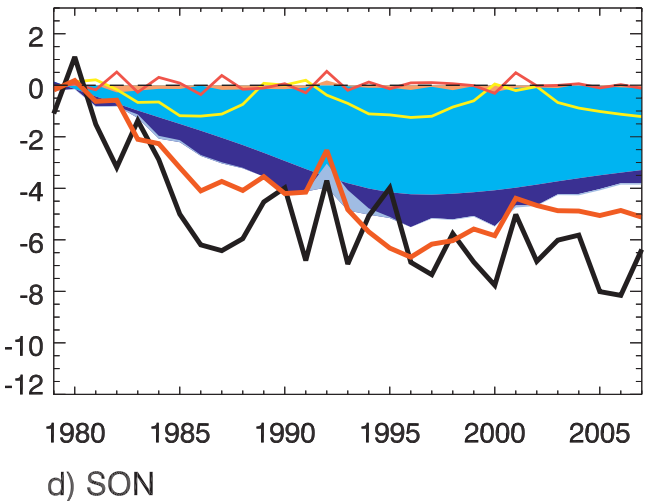

d) SON

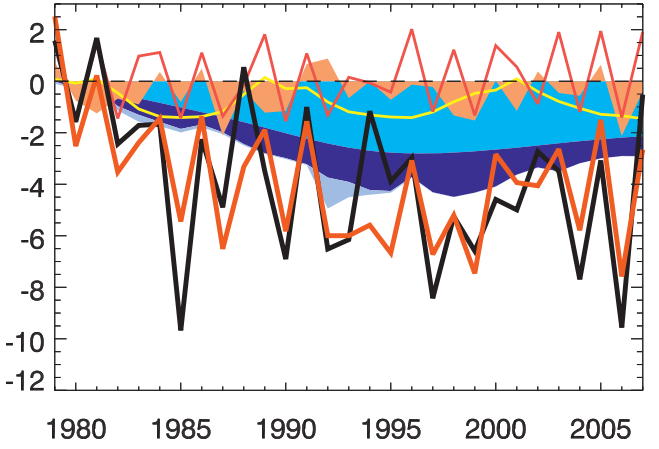

f) post-Pinatubo period

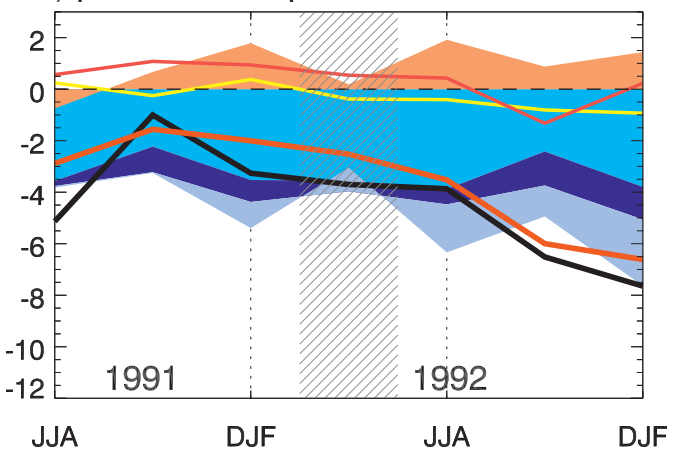

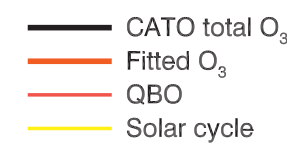

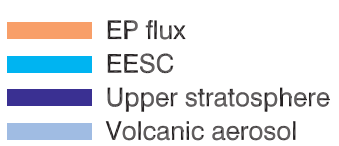

FIG. 3. Seasonal and annual evolution of SH $\left(42^{\circ}-60^{\circ} \mathrm{S}\right.$ EL) column ozone anomalies from 1979 to 2007 , scaled to the 1979-80 mean, showing (a) DJF, (b) MAM, (c) JJA, (d) SON, (e) annual mean, and (f) the post-Pinatubo period (JJA 1992-DJF 1993). The upper stratosphere fraction is directly calculated from SBUV version 8 profile data above $10 \mathrm{hPa}$ (see text for details). The contributions attributed to the release of ODS in the LS (EESC), upper stratospheric ozone loss (Upper stratosphere), volcanic eruptions (Volcanic aerosol), and EP flux are shown as colored areas stacked on top of each other. The contributions from the solar cycle and QBO are shown as yellow and brown lines, respectively. CATO total ozone anomalies and the fit of the statistical model are shown in black and red lines, respectively. In (e), the post-Pinatubo period is additionally indicated as gray shading. The hatched period in (f) indicates MAM 1992, for which the regression provided a positive volcanic coefficient (see text for more details).

circulation is driven by breaking extratropical planetary waves (Holton et al. 1995). The transformed Eulerian mean (TEM) formulation of the stratospheric circulation, referred to as residual (mean meridional) circulation, approximates the Lagrangian motions in the stratosphere. The residual circulation is described by the meridional and vertical residual velocities $\left[v^{*}\right]$ and $\left[w^{*}\right]$, with the square brackets denoting zonal means. Here, we have 
derived $\left[v^{*}\right]$ and $\left[w^{*}\right]$ in log pressure coordinates; $\left[v^{*}\right]$ was calculated according to Andrews et al. (1987). Since vertical velocity is not available from NNR for stratospheric levels, $\left[w^{*}\right]$ was derived by calculating the residual streamfunction $\Psi$ from $\left[v^{*}\right]$ and then integrating $\Psi$ over latitude [Rosenlof 1995; see her Eq. (6)].

The concept of the EP flux and its divergence provides a powerful tool to diagnose large-scale wave activity and how the latter interacts with the zonal-mean zonal wind (Eliassen and Palm 1961; Andrews and McIntyre 1976, 1978). In this study, the quasigeostrophic forms of the EP flux $\left\{\hat{F}_{\varphi}, \hat{F}_{z}\right\}$ and the EP flux divergence $\Delta$ were calculated in log pressure coordinates after Dunkerton et al. (1981). To account for the decreasing magnitude of the EP vectors over the troposphere-stratosphere domain, we have multiplied their magnitudes by the factor $\exp (z / H)$, approximately equivalent to dividing by density. The scaling results in significant reductions (increases) of EP vector lengths in the lower troposphere (stratosphere), but does not largely affect vector lengths in the upper troposphere/lowermost stratosphere. There, as a consequence, vector lengths may appear falsely small compared to altitudes below and above. (The EP flux divergence is displayed in Figs. 7 and 8 for completeness but is not discussed further in the text).

Both stationary and transient atmospheric waves are characteristic features of the general circulation. While the term "stationary waves" refers to the zonally asymmetric features of the time-averaged atmospheric circulation, transient motions denote instantaneous departures of the flow from its mean state (e.g., Nigam and DeWeaver 2003). To investigate vertical wave propagation and wave-mean flow interaction, the EP flux and divergence have been calculated separately for transient and stationary disturbances. For this purpose, the momentum and sensible heat flux terms were decomposed in a simple mathematical framework (Karoly et al. 1999), shown for the heat flux:

$$
[\overline{v T}]=[\bar{v}][\bar{T}]+\left[\bar{v}^{*} \bar{T}^{*}\right]+\left[\overline{v^{\prime} T^{\prime}}\right] .
$$

The total flux is due to transports by the (steady) mean meridional circulation and by the stationary and transient eddies, respectively. Brackets indicate the zonal average and the overbar the time average. Primes describe deviations from the time mean. In contrast to the definition of the residual velocities, where the star denotes the residual, here the star represents deviations from the zonal mean. As both notations for residual velocities and eddy fluxes are standard notations, they will be kept differently, but consistently, throughout the paper.

\section{Results and discussion}

\section{a. Multiple regression analysis of CATO total ozone}

The seasonal and annual evolution of southern midlatitude total ozone anomalies from 1979 to 2007 and the major processes influencing long-term changes are shown in Fig. 3. Its design follows Fig. 2 of Harris et al. (2008), which shows the respective CATO long-term changes at $\mathrm{NH}$ midlatitudes.

The largest single cause for the total ozone decline from 1979 to the mid-1990s was the EESC increase, which accounted for a maximum net column decline of $3 \%-4 \%$ depending on the season. Upper stratospheric ozone decreases resulting from homogeneous chemistry caused another seasonally variable loss of up to $1.5 \%-2 \%$. The maximum total effect of ODSs (EESC + upper stratosphere) thus amounted to $-4 \%$ to $-6 \%$ depending on the season and occurred in the second half of the 1990s in agreement with the maximum ODS loading (Fig. 1).

The QBO is responsible for a nonnegligible fraction of the interannual variability at $\mathrm{SH}$ midlatitudes accounting for annual mean total ozone variations of a little less than $1 \%$ (Fig. 3e). The fact that the ozone QBO is strongly modulated by the seasonal cycle, showing largest extratropical anomalies in austral winter and spring (Bowman 1989; Hamilton 1989; Lait et al. 1989), is well captured in the analysis: that is, modeled QBO variability during JJA and SON is more than double the DJF variability.

Year-to-year variations of SH midlatitude ozone are essentially associated with combined variations in the 11-yr solar cycle, the QBO, and planetary wave activity. Prominent examples are the negative total ozone anomalies in 1985, 1997, and 2006, which can be explained by the combined effects of a solar cycle minimum, the westerly phase of the QBO, and a negative EP flux anomaly (1985 and 2006) (see also Bodeker et al. 2007).

The solar cycle leads to decadal-scale variations of about $1 \%-1.5 \%$ from solar minimum to maximum (Fig. 3e). As described by Brunner et al. (2006b), this effect is somewhat smaller than in other studies, which quantified its contribution to $2 \%-3 \%$ (WMO 2007). Possibly the smaller effect is related to using EESC and not a linear trend in the regression model (Dhomse et al. 2006).

Interannual variations in upwelling planetary wave activity entering the LS, expressed by $F_{z}$, have a significant influence on midlatitude total ozone variability. In contrast to the $\mathrm{NH}$, where planetary wave activity significantly impacts midlatitude total ozone variability during winter only (Harris et al. 2008), $F_{z}$ considerably contributes to interannual variability during all seasons except MAM, when upward propagation of planetary waves is impeded by stratospheric easterly winds. 


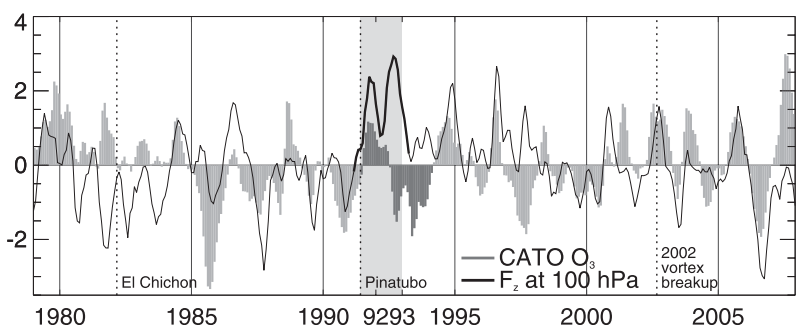

FIG. 4. Post-Pinatubo anomalies of CATO midlatitude $\left(42^{\circ}-60^{\circ} \mathrm{S}\right.$ EL) total ozone (dark gray shading) and the accumulated midlatitude $\left(45^{\circ}-75^{\circ} \mathrm{S}\right) F_{z}$ at $100 \mathrm{hPa}$ (thick black line). The full ozone and $F_{z}$ time series, which are deseasonalized, detrended, normalized by one standard deviation, and smoothed using a threemonthly running mean, have been displayed as a thin black line and light gray shading, respectively. Vertical dotted lines indicate the eruptions of El Chichón in March 1982, Mt. Pinatubo in June 1991, and the breakup of the stratospheric vortex in September 2002. The post-Pinatubo period of June 1991-1992 is highlighted by gray shading; $F_{z}$ is as in section $4 \mathrm{a}$.

Following the Mt. Pinatubo eruption, annual mean CATO midlatitude total ozone decreased by up to $4 \%$ in the NH (Harris et al. 2008). This reduction occurred entirely in line with the temporal development of the volcanic aerosol loading, clearly attributing the ozone anomaly to the effects of the volcanic aerosol (Harris et al. 2008). However, at SH midlatitudes, no pronounced negative anomaly occurred in the aftermath of the eruption (Fig. 3).

Regarding the cause(s) for the lack of the signal, the regression analysis provides the crucial clue pointing to both QBO and planetary wave activity as responsible processes, with planetary wave activity having the major effect. As expected, the regression model attributes ozone loss of a few percent to the effect of volcanic aerosols (Fig. 3f). This loss is significantly smaller than in the $\mathrm{NH}$ (Harris et al. 2008), most probably due to attribution difficulties of the aerosol and EP flux proxy (cf. section 3a). During SON 1991, when the aerosol-induced chemical ozone depletion was still insignificant, the QBO and planetary wave activity together were responsible for increasing total ozone, resulting in a positive column anomaly (Figs. 3f and 4). During DJF 1991/92, the QBOinduced increase and the chemically caused decrease approximately balanced. However, the chemical decrease was additionally counteracted by wave activity, resulting in the continuation of the positive total ozone anomaly. The QBO changed to the west phase during the second half of 1992, then causing slightly negative extratropical ozone anomalies. Still, the volcanically induced ozone depletion was counteracted by continued wave activity during JJA 1992 and SON 1992. Hence, the effect of the wave activity was to counteract chemical ozone depletion and to delay the

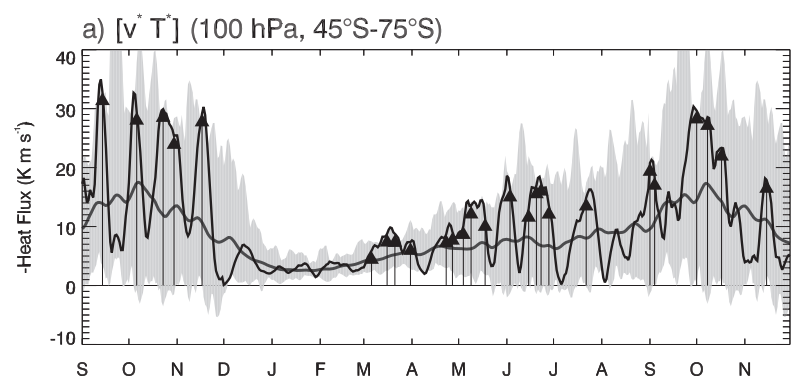

b) $\left[\mathrm{T}^{\prime}\right]\left(55^{\circ} \mathrm{S}-75^{\circ} \mathrm{S}\right)$

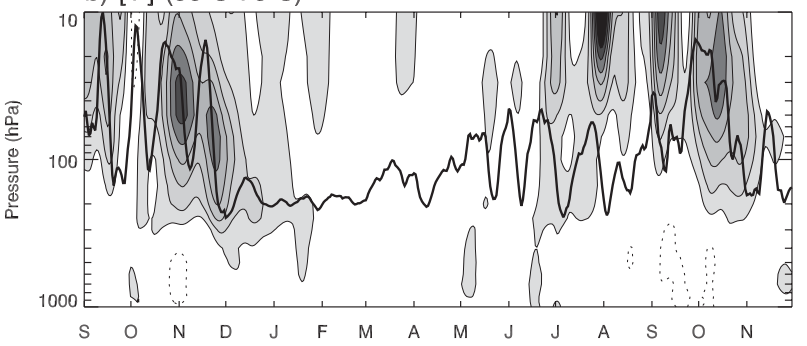

c) $\left[\mathrm{u}^{\prime}\right]\left(20^{\circ} \mathrm{S}-90^{\circ} \mathrm{S}\right)$

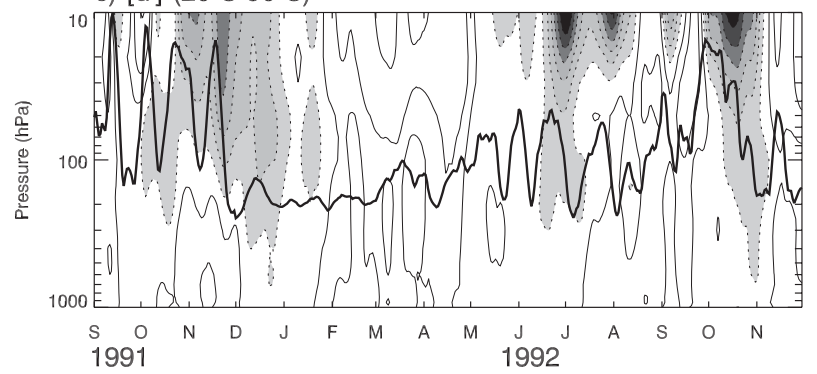

FIG. 5. (a) Daily eddy heat flux $\left[v^{*} T^{*}\right]\left(\mathrm{K} \mathrm{m} \mathrm{s}^{-1}\right)$ at $100 \mathrm{hPa}$, averaged over $45^{\circ}-75^{\circ} \mathrm{S}$ (black line) for September 1991-November 1992. The dark gray line displays the 1979-2007 average, and the gray shading indicates the range of values observed between 1979 and 2007. The black arrows indicate the peaks of the SWEs listed in Table 3. (b) Daily temperature departures $\left[T^{\prime}\right]$ from the 1979-2007 mean, averaged over $55^{\circ}-75^{\circ} \mathrm{S}$. Contour intervals are $\pm 1 \mathrm{~K}$; negative contours are dashed. (c) Daily zonal-mean zonal wind departures $\left[u^{\prime}\right]$ from the $1979-2007$ mean, averaged over $20^{\circ}-$ $90^{\circ} \mathrm{S}$. Contour intervals are $\pm 1 \mathrm{~m} \mathrm{~s}^{-1}$; negative contours are dashed. All time series displayed in (a)-(c) have been smoothed using a 7-day running mean. The daily eddy heat flux is also shown in (b) and (c). The primes denote temporal departures from the long-term mean, the asterisks departures from the zonal mean, and the square brackets the zonal mean. Figure adopted from Newman and Nash (2005).

onset of a visible volcanic effect into the second half of 1992.

\section{b. Effects of wave activity on stratospheric dynamics}

The year 1992 showed the single largest anomaly in SH midlatitude LS planetary wave activity in the whole period from 1979 to 2007 (Fig. 4). It consisted of several episodes of significant wave activity during March, AprilJuly, September, and October 1992 (Fig. 5a), which were well above the climatological average (thick gray line). 
TABLE 3. Significant $1991 / 92$ SWEs as given by the 100 -hPa eddy heat flux averaged over $45^{\circ}-75^{\circ} \mathrm{S}$. Dates represent the peak in daily eddy heat flux; $R$ denotes a daily record amplitude during the 1979-2007 period. The number of days per event is determined by when the sign of the first derivative changes on either side of the peak. Further columns are amplitude of maximum eddy heat flux (K $\left.\mathrm{m} \mathrm{s}^{-1}\right)$, tendency of temperature $\Delta T(\mathrm{~K})$ at $30 \mathrm{hPa}$, zonal-mean zonal wind $\Delta u$ at $20 \mathrm{hPa}\left(\mathrm{m} \mathrm{s}^{-1}\right)$ between onset of the wave event and four days after the maximum wave activity, and time lag (days) between the preceding tropospheric maximum of zonal-mean daily wave activity $\left[v^{*} T\right]$ at $300 \mathrm{hPa}$ and peak date at $100 \mathrm{hPa}$ (cf. Fig. 9), indication of tropospheric blocking preceding the SWE, and region of blocking. An interval of four days to determine $\Delta T$ and $\Delta u$ has been chosen because the correlation between maximum wave activity at $100 \mathrm{hPa}$ and temperature anomalies at $30 \mathrm{hPa}$ maximizes there. $\mathrm{SFW}=$ stratospheric final warming, STRAT $=$ stratospheric anomaly propagating downward. Regions of blocking: SEP = southeastern Pacific, SWP = southwestern Pacific, ATL = Atlantic, AUS = Australia, SA = South America, and AFR = Africa. The classification into SEP or SWP blocking was made using $150^{\circ} \mathrm{W}$ as demarcation longitude.

\begin{tabular}{|c|c|c|c|c|c|c|c|}
\hline Date & $\begin{array}{l}\text { Duration } \\
\text { (days) }\end{array}$ & $\begin{array}{l}\text { Amplitude } \\
\left(\mathrm{K} \mathrm{m} \mathrm{s}^{-1}\right)\end{array}$ & $\Delta T(\mathrm{~K})$ & $\Delta u\left(\mathrm{~m} \mathrm{~s}^{-1}\right)$ & $\begin{array}{c}\text { Lag (days) } \\
300 / 100 \mathrm{hPa}\left[v^{*} T^{*}\right]\end{array}$ & $\begin{array}{l}\text { Preceding } \\
\text { blocking }\end{array}$ & Region \\
\hline 14 Sep $1991(R)$ & 8 & -49.8 & 2.3 & -2.5 & 2 & Yes & ATL, AUS \\
\hline 6 Oct 1991 & 7 & -41.1 & 5.5 & -1.5 & 1 & Yes & SA, SWP \\
\hline 23 Oct 1991 & 7 & -38.3 & 3.0 & -1.8 & 0 & Yes & SEP, SWP \\
\hline 30 Oct 1991 & 6 & -32.1 & 0.6 & -0.8 & 0 & No & \\
\hline 17 Nov $1991(R)$ SFW & 14 & -34.9 & 0.5 & -2.7 & & & \\
\hline 6 Mar $1992(R)$ & 6 & -8.3 & -0.1 & 0.8 & 2 & Yes & ATL \\
\hline $16 \operatorname{Mar} 1992(R)$ & 5 & -11.0 & 0.6 & -1.0 & 3 & Yes & SEP \\
\hline 21 Mar $1992(R)$ & 7 & -12.2 & 0.4 & -1.0 & STRAT & & \\
\hline 31 Mar $1992(R)$ & 9 & -11.0 & -0.03 & 0.05 & 2 & No & \\
\hline 23 Apr 1992 & 6 & -11.3 & 0.2 & -0.1 & 1 & Yes & SWP \\
\hline 27 Apr 1992 & 5 & -12.9 & -0.02 & -1.1 & 1 & Yes & SEP, AUS \\
\hline 4 May $1992(R)$ & 6 & -16.6 & 0.1 & -0.8 & 0 & Yes & SEP \\
\hline 9 May $1992(R)$ & 7 & -19.8 & 0.3 & -0.3 & 1 & Yes & SEP, SWP \\
\hline 18 May $1992(R)$ & 5 & -17.5 & 0.4 & -0.7 & 1 & Yes & SEP, AUS \\
\hline 3 Jun $1992(R)$ & 8 & -25.0 & 0.9 & -1.0 & 1 & No & \\
\hline 15 Jun 1992 & 6 & -20.2 & -0.9 & -1.0 & 1 & Yes & SEP, SWP, IND \\
\hline 20 Jun 1992 & 4 & -19.8 & 2.5 & -2.0 & 2 & Yes & SEP \\
\hline 23 Jun 1992 & 5 & -20.3 & 1.4 & -1.9 & 0 & Yes & SEP, SWP \\
\hline 28 Jun 1992 & 8 & -19.5 & 1.3 & -1.7 & 1 & Yes & SEP \\
\hline 22 Jul 1992 & 8 & -19.6 & 1.1 & -1.6 & 1 & Yes & SA \\
\hline 1 Sep 1992 & 5 & -20.4 & 5.5 & -3.2 & 2 & No & \\
\hline 4 Sep 1992 & 5 & -25.9 & 2.0 & -1.5 & STRAT & & \\
\hline 1 Oct $1992(R)$ & 7 & -36.6 & 1.9 & -2.7 & STRAT & & \\
\hline 8 Oct 1992 & 5 & -35.8 & 2.3 & -3.1 & STRAT & & \\
\hline 17 Oct 1992 & 9 & -41.0 & -2.6 & -2.0 & 2 & Yes & AFR, SWP \\
\hline 15 Nov 1992 SFW & 12 & -24.6 & -0.5 & 0.9 & & & \\
\hline
\end{tabular}

The anomaly in 1992 was preceded by another positive anomaly during austral spring 1991 (Fig. 4), which resulted from five extremely large stratospheric wave events (SWEs) during SON of 1991 (Table 3; Fig. 5a). A considerable fraction of these events were record-breaking events (i.e., wave activity for a given day in 1991/92 was the largest in the whole record of daily wave activity over 1979-2007; Table 3).

According to theory (e.g., Salby 2008), the effect of breaking planetary waves is to decelerate the westerly flow in the extratropical stratosphere and to warm midlatitudes. In fact, extended periods in 1991/92 were characterized by smaller than average zonal wind speeds and higher than average temperatures (Figs. 5b,c). With the exception of March 1992, when the easterly flow (Fig. 5 b) largely suppressed upward propagation of planetary waves into the stratosphere and the stratospheric final warming (SFW) in 1992, every wave event led to reduced extratropical mean $\mathrm{SH}$ zonal mean velocities by a few tenths of a meter per second up to more than $3 \mathrm{~m} \mathrm{~s}^{-1}$ (Table 3, $\Delta u$ ). The waves also impacted stratospheric temperatures in the polar vortex collar region $\left(55^{\circ}-75^{\circ} \mathrm{S}\right)$, resulting in a warming of a few tenths to a few degrees (Table $3, \Delta T$ ) a few days after each wave event. Note that this high midlatitude warming due to the waves was as large as or larger than the tropical temperature increase from volcanic radiative heating (e.g., Karpechko et al. 2010). Hence, an increase of the LS equator-to-pole temperature gradient as occurred in the NH in 1992/93 (Graf et al. 2007; Stenchikov et al. 2002) did not develop in the SH. During spring 1991, the effects of the anomalous LS wave activity also included a shift in the Antarctic polar vortex toward the southern parts of South America (H. Rieder et al. 2011, unpublished manuscript).

These results indicate that the Brewer-Dobson circulation of the period September-November 1992 was 
a)

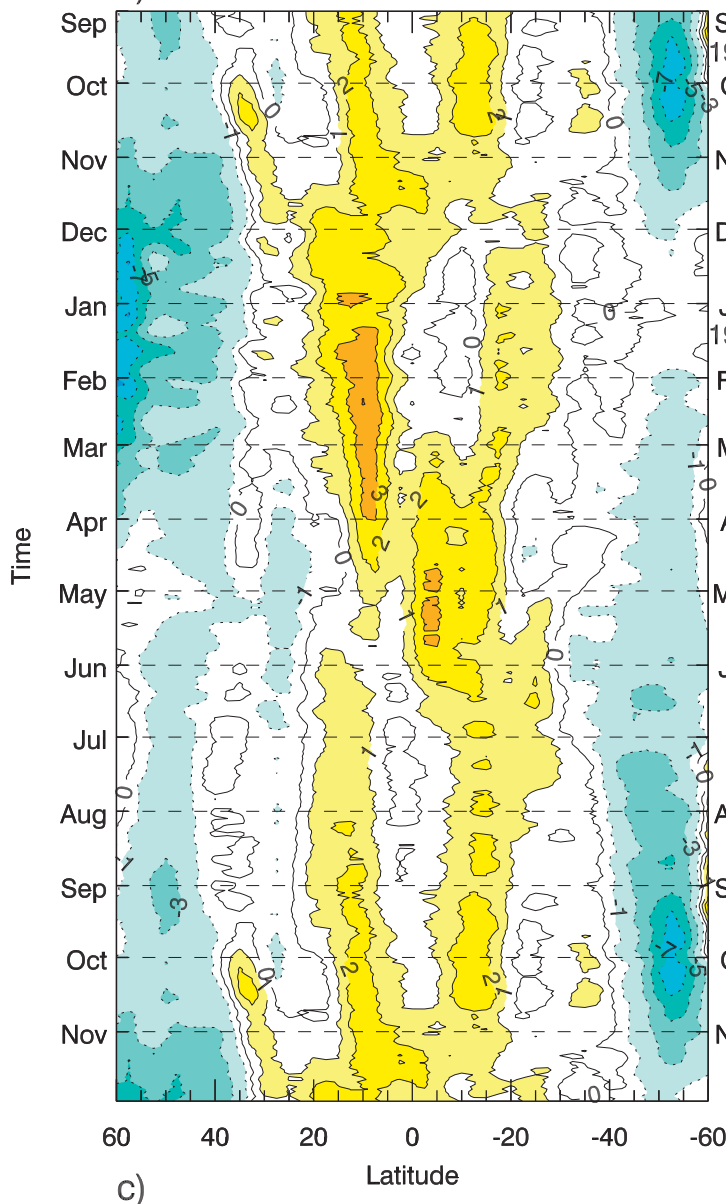

b)

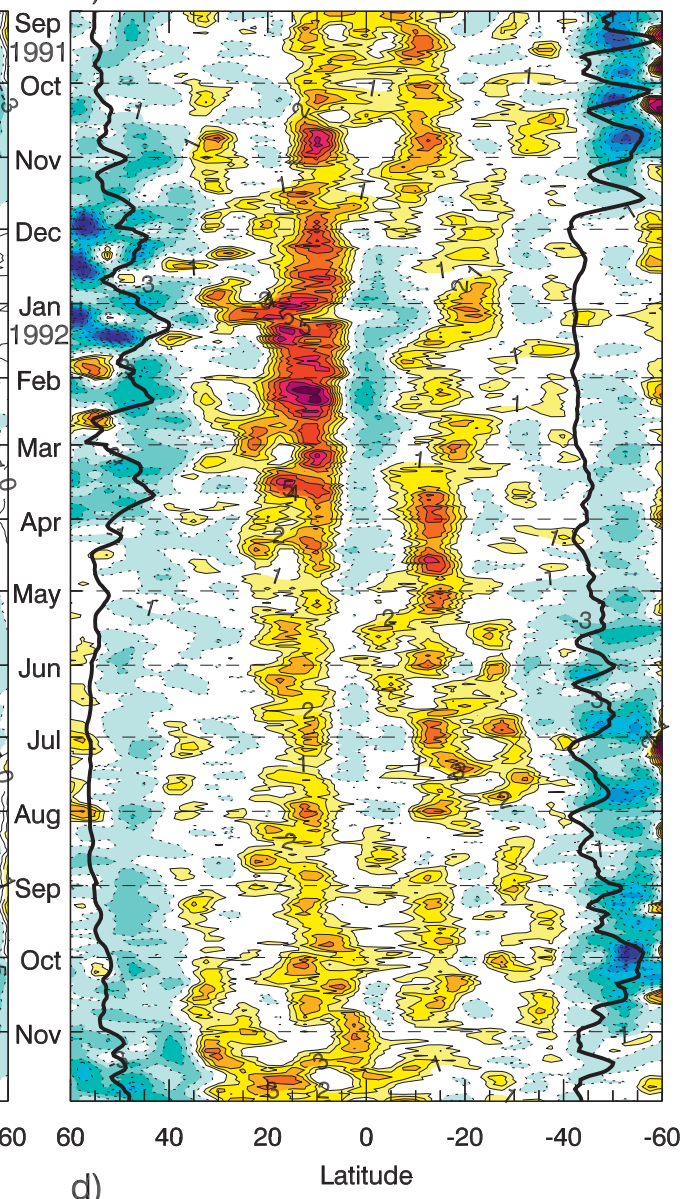

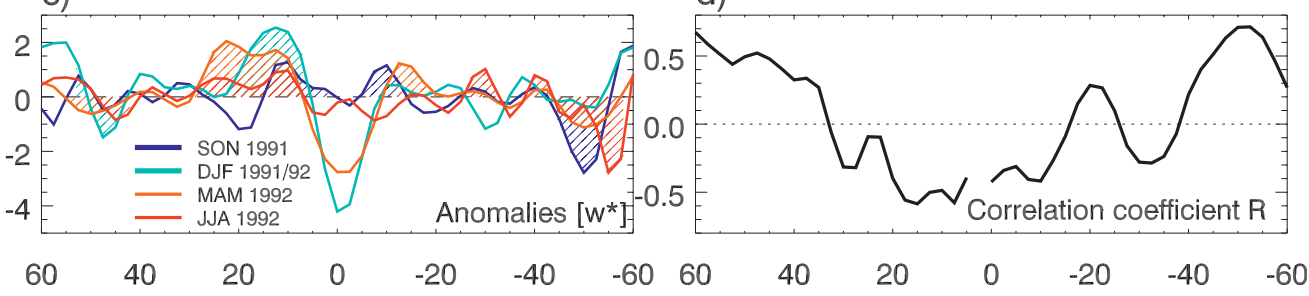

FIG. 6. (a) Long-term mean (1979-2007) [ $\left.w^{*}\right]$ at $70 \mathrm{hPa}$ as a function of latitude and time $\left(10^{-1} \mathrm{~mm} \mathrm{~s}^{-1}\right)$. Contour intervals are $1 \times 10^{-1} \mathrm{~mm} \mathrm{~s}^{-1}$ for the positive contours and $-2 \times 10^{-1} \mathrm{~mm} \mathrm{~s}^{-1}$ starting at $-1 \times 10^{-1} \mathrm{~mm} \mathrm{~s}^{-1}$ for the negative contours. Positive (negative) values of $\left[w^{*}\right]$ indicate upwelling (downwelling). (b) As in (a), but for September 1991-November 1992. The SH eddy heat flux curve from Fig. 5a has been overlaid as solid black line. Additionally, the $45^{\circ}-57^{\circ} \mathrm{N} \mathrm{NH}$ eddy heat flux series is displayed. The magnitudes of $\mathrm{NH}$ and $\mathrm{SH}$ eddy heat fluxes have been adapted to fit the graph. (c) Seasonal mean deviations of the 1991/92 [ $\left.w^{*}\right]\left(10^{-1} \mathrm{~mm} \mathrm{~s}^{-1}\right)$ from the longterm seasonal mean for those seasons, in which significant deviations from the LTM occurred: SON 1991, DJF 1991/ 92, MAM 1992, and JJA 1992. (d) Latitude-dependent Pearson correlation coefficient between [ $\left.w^{*}\right]$ at $70 \mathrm{hPa}$ and $\mathrm{SH}(\mathrm{NH})$ midlatitude eddy heat flux at $100 \mathrm{hPa}$ is shown in the $\mathrm{SH}(\mathrm{NH})$. All data have been smoothed using a 7-day running mean.

considerably enhanced compared to the long-term mean (LTM). To verify this assumption, daily residual vertical velocities were calculated as a function of latitude (section 3b), and the LTM values of the period 19792007 are compared with those in 1991/92 (Fig. 6). For completeness, the $\mathrm{NH}$ is also displayed but only marginally discussed. In the $\mathrm{SH}$, there is a distinct seasonal cycle in the residual motion with no or only little downwelling at $40^{\circ}-60^{\circ} \mathrm{S}$ during DJF 1992 and maximum downward motion during the spring (SON) seasons of both years (Fig. 6b). By comparing the post-Pinatubo period with the reference period 1979-2007 (Fig. 6c), we 
can demonstrate that the mean residual downwelling was significantly increased from September 1991 to July 1992, downward velocities being larger by more than half to about double the climatological values depending on the season. The analysis nicely illustrates the wave driving of the extratropical residual circulation; that is, every SWE in 1991/92 caused a short-term enhancement of the midlatitude downward vertical velocity (Fig. 6b), also represented by the high midlatitude correlation between the poleward eddy heat flux at $100 \mathrm{hPa}$ and [ $w^{*}$ ] at $70 \mathrm{hPa}$ (Fig. 6d). Using a radiative transfer model, Kinne et al. (1992) showed that increased upward motions were induced by aerosol heating in the tropical stratosphere in the months following the eruption. Increased upwelling by more than $50 \%$ of the climatological mean is also seen in the NNR data from SON 1991 to July 1992 (Figs. 6b,c). While a significant part of it was certainly caused by aerosol heating, some of the tropical upwelling may have been triggered by the SWEs since the upwelling occurred quasi-simultaneously with enhanced downwelling at midlatitudes (Fig. 6b), expressed also by a negative correlation between $\left[w^{*}\right]$ and the midlatitude eddy heat flux in the tropics (Fig. 6d). In turn, more vigorous midlatitude downwelling also occurred during DJF 1991/92 ( 40\%) when upward propagation of planetary waves is suppressed. This leads us to suggest that the large-scale circulation changes of this season were at least partly induced by the tropical aerosol heating and associated anomalous upward motion. A similar tropical-extratropical pattern is also seen during boreal summer 1992 in the NH supporting this notion. Altogether, our results indicate that both aerosol heating and dissipating planetary waves worked together in causing a largely enhanced Brewer-Dobson circulation in the year after the Pinatubo eruption.

In the following we will show that the anomalous LS planetary wave activity was closely connected to pronounced circulation anomalies in the troposphere. To investigate the vertical propagation of planetary waves from the troposphere to the stratosphere, we have separated wave activity into stationary and transient components. This is useful because only the longest waves, mostly contained in the stationary component, may propagate into the middle atmosphere (Charney and Drazin 1961).

\section{c. Coupling to tropospheric dynamics}

In the troposphere, there is a rich spectrum of extratropical waves at the synoptic and planetary scale. In the $\mathrm{SH}$, the absence of mountain chains locking the phase of planetary waves implies that atmospheric variability is mostly accounted for by transient (traveling) waves (James 1994), and that stationary wave amplitudes are
TABLE 4. Lengths and latitudes of transient and stationary EP vectors in the LTM (1979-2007) and the 1991/92 relative deviations from the LTM (\%) at the latitudes of maximum wave flux, in the lower stratosphere $(30 \mathrm{hPa})$ and the troposphere $(500 \mathrm{hPa})$; cf. Figs. 7 and 8 . The vector lengths of the LTM rows need to be multiplied by $10^{18}$ to obtain the true vector lengths.

\begin{tabular}{|c|c|c|c|c|}
\hline Wave component & $\begin{array}{l}\text { SON } \\
1991\end{array}$ & $\begin{array}{c}\text { MAM } \\
1992\end{array}$ & $\begin{array}{c}\text { JJA } \\
1992\end{array}$ & $\begin{array}{l}\text { SON } \\
1992\end{array}$ \\
\hline \multicolumn{5}{|c|}{ Lower stratosphere } \\
\hline Transient $\left(57.5^{\circ} \mathrm{S}\right)$ & 3.7 & 1.6 & 4.1 & 3.7 \\
\hline Stationary $\left(60^{\circ} \mathrm{S}\right)$ & 4.1 & 0.6 & 1.9 & 4.1 \\
\hline \multicolumn{5}{|c|}{ Anomalies: $(1991 / 92-$ LTM $) /$ LTM $\times 100(\%)$} \\
\hline Transient $\left(57.5^{\circ} \mathrm{S}\right)$ & 27 & 41 & 7 & 11 \\
\hline Stationary $\left(60^{\circ} \mathrm{S}\right)$ & 55 & 53 & 85 & 27 \\
\hline \multicolumn{5}{|c|}{$\begin{array}{c}\text { Troposphere } \\
\text { 1979-2007 }\end{array}$} \\
\hline Transient $\left(45^{\circ} \mathrm{S}\right)$ & 136 & 135 & 185 & 136 \\
\hline Stationary $\left(32.5^{\circ} \mathrm{S}\right)$ & 6.5 & 7.7 & 16.6 & 6.5 \\
\hline Stationary $\left(57.5^{\circ} \mathrm{S}\right)$ & 6.2 & 5.2 & 12.9 & 6.2 \\
\hline Stationary $\left(75^{\circ} \mathrm{S}\right)$ & 5.7 & 6.3 & 5.1 & 5.7 \\
\hline \multicolumn{5}{|c|}{ Anomalies: $(1991 / 92-$ LTM $) /$ LTM $\times 100(\%)$} \\
\hline Transient $\left(45^{\circ} \mathrm{S}\right)$ & -10 & -20 & -9 & -14 \\
\hline Stationary $\left(32.5^{\circ} \mathrm{S}\right)$ & 10 & 29 & -26 & 82 \\
\hline Stationary $\left(57.5^{\circ} \mathrm{S}\right)$ & 106 & 181 & 78 & 45 \\
\hline Stationary $\left(75^{\circ} \mathrm{S}\right)$ & 92 & -22 & -12 & 46 \\
\hline
\end{tabular}

much smaller than their northern counterparts (van Loon and Jenne 1972). The relative importance of transient versus stationary waves is also reflected in the magnitudes of tropospheric EP fluxes over 1979-2007, which are a factor of 10-35 larger for transient than for stationary waves (Table 4). Transient wave activity is found over a broad range of latitudes, with the largest upward directed fluxes centered near $40^{\circ}-45^{\circ} \mathrm{S}$ (Hartmann et al. 1984). The characteristics of SH stationary waves have been discussed extensively in the literature (e.g., van Loon and Jenne 1972; Hartmann 1977; Trenberth 1980; Karoly 1985, 1989; Randel 1988; Quintanar and Mechoso 1995; Hurrell et al. 1998). The SH stationary EP fluxes show three distinct maxima in the subtropics, at high midlatitudes, and over Antarctica (Fig. 7; Table 4). The midlatitude and polar peaks have been linked to the presence of landmasses, the Antarctic orography, surface thermal forcing, and forcing from lower latitudes (van Loon and Jenne 1972; Hurrell et al. 1998; Quintanar and Mechoso 1995). The subtropical stationary wave activity has been associated with land-sea contrasts, the Asian monsoon, and the Pacific Walker circulation, and its interannual variability is closely coupled to ENSO (Trenberth 1980). Owing to an equivalent barotropic structure, $\mathrm{SH}$ stationary waves usually transport only little sensible heat poleward most of the year (e.g., Trenberth 1980). Thus, vertical propagation is weak, which is also 


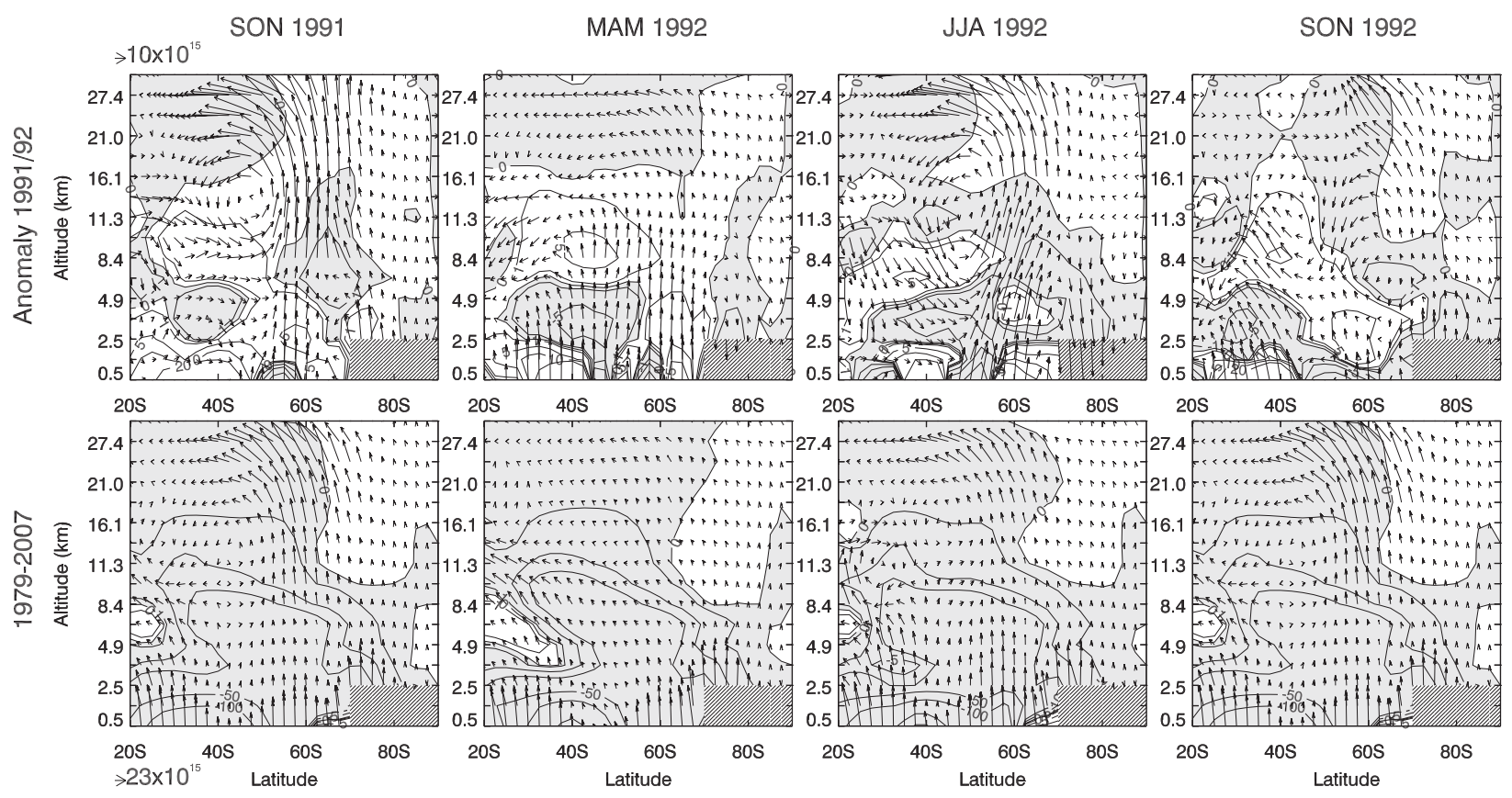

FIG. 7. Stationary waves. Seasonal mean EP fluxes and divergence in the SH extratropics $\left[F_{\varphi}\left(\mathrm{kg} \mathrm{m} \mathrm{s}^{-2}\right)\right.$ and $\left.F_{z}\left(\mathrm{~kg} \mathrm{~m}^{2} \mathrm{~s}^{-2}\right)\right]$. EP vectors have been multiplied by $\exp (z / H)$. Vector scaling is identical for all climatological means and anomalies, respectively, and scaling vector lengths are indicated at the bottom and top for climatological means and anomalies, respectively. EP flux divergence is indicated by contours at $0, \pm 1, \pm 5, \pm 10, \pm 50, \pm 100, \pm 1000 \times 10^{15} \mathrm{~kg} \mathrm{~m} \mathrm{~s}^{-2}$. Shaded areas denote EP flux convergence (LTM) or where EP divergence in 1991/92 is less divergent/more convergent than in the LTM (anomalies 1991/92). (top) Anomalous EP fluxes and divergence in 1991/92 (1991/92 - 1979-2007); (bottom) climatological means of the period 1979-2007 during (left) SON (1991), (left middle) MAM (1992), (right middle) JJA (1992), and (right) SON (1992). The region of the Antarctic is represented by a hatched box.

reflected in LTM stationary EP flux magnitudes derived from NNR (Table 4). Only during SH spring is there significant upward propagation of stationary waves into the middle atmosphere at $50^{\circ}-60^{\circ} \mathrm{S}$ (Fig. 7), indicating that those waves are strongly baroclinic and couple with the stratospheric circulation. The stationary waves dominate over the transients in the LS during this season (Table 4; Randel 1988).

Pronounced anomalies in transient and stationary EP fluxes occurred in the post-Pinatubo period. In the stratosphere, the strengthened wave-driven part of the Brewer-Dobson circulation was due to both enhanced stationary and transient wave activity (Figs. 7 and 8; Table 4), visible as reverse overturning cells in the anomaly graphs of Figs. 7 and 8. The increases were particularly pronounced for the stationary component from SON 1991 to JJA 1992 (Table 4). The midlatitude wave flux enhancement was weaker during spring 1992 (Table 4), and an enhanced driving of the BrewerDobson circulation is detectable only for the transient waves (Fig. 8).

In the troposphere, while some enhanced transient wave flux is discernible during both spring seasons and JJA 1992 at high latitudes (Fig. 8), subtropical and midlatitude transient wave activity was reduced by $10 \%-$ $20 \%$ compared to the LTM in the whole period and throughout the troposphere (Fig. 8; Table 4). In contrast, stationary wave activity was enhanced by $80 \%-180 \%$ at midlatitudes from SON 1991 through JJA 1992 (Fig. 7; Table 4 ) and by $45 \%-90 \%$ at polar latitudes during both spring seasons. For winter 1992, our results essentially point to the same anomaly presented by Newman and Nash (2005) in their analysis of the 2002 winter: they showed that the 1992 planetary wave-1 amplitude at $50^{\circ}-70^{\circ} \mathrm{S}$ and $700 \mathrm{hPa}$ exhibited the second-highest amplitude after 2002.

At midlatitudes, the increased stationary wave activity propagated into the LS (Fig. 7). This pattern is particularly pronounced during SON 1991 and JJA 1992, where a clear vertical band of EP fluxes extends from the surface into the LS connecting to stratospheric stationary wave activity. Interestingly, we find increased poleward horizontal EP fluxes out of the subtropics into midlatitudes at middle to upper tropospheric levels during SON 1991 and JJA 1992, potentially indicating a coupling of processes at lower and higher latitudes. Similarly, for the 2002 winter, Newman and Nash (2005) showed that subtropical wave energy propagated 

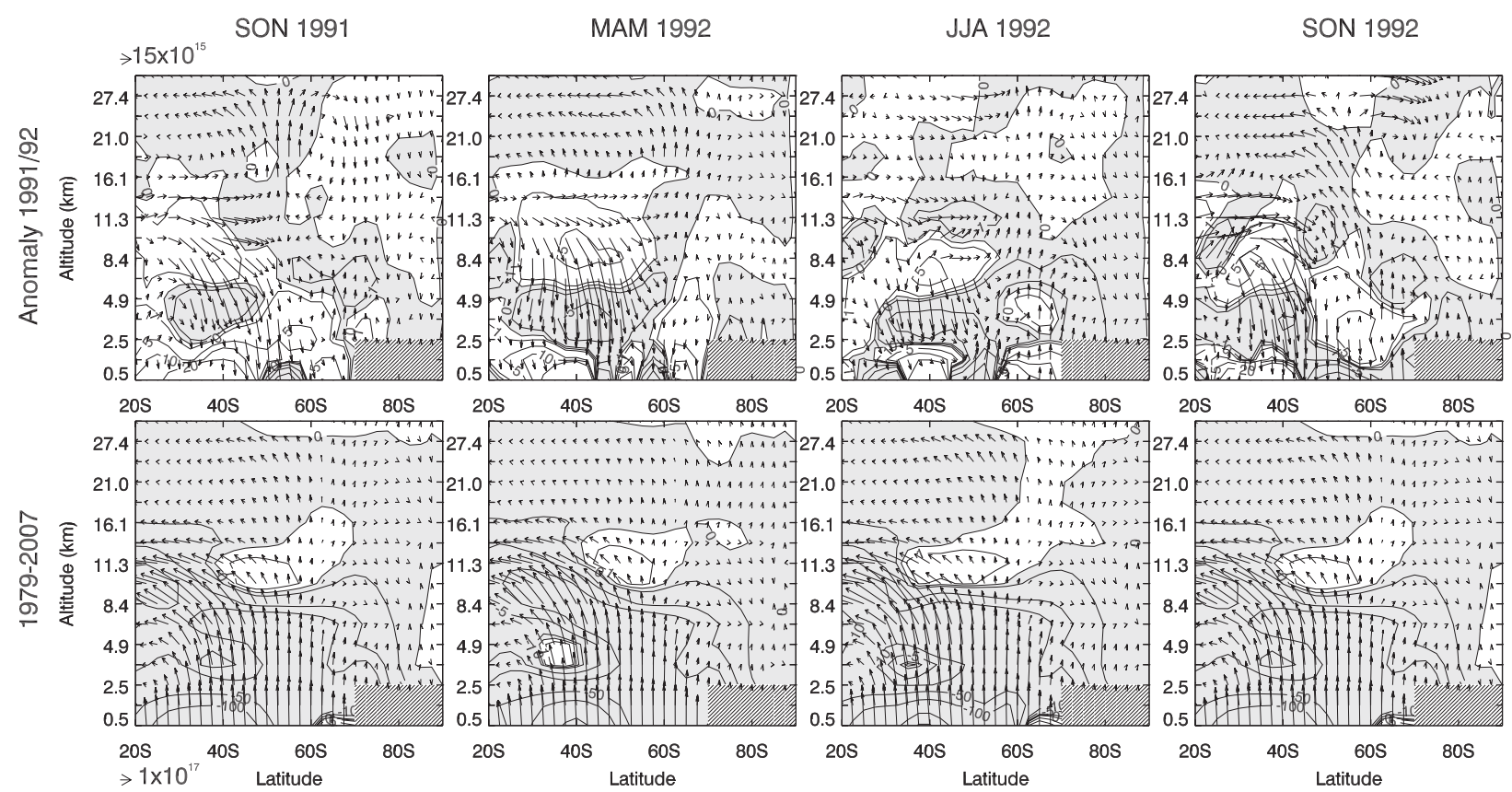

FIG. 8. As in Fig. 7, but for transient waves.

southward, reinforcing wave 1 at midlatitudes, which then propagated upward into the stratosphere. Considering the similar tropospheric flow constellations in 1991/92 and 2002 (negative SAM, ENSO warm phase; see our Fig. 10), it seems plausible that similar mechanisms lead to the anomalous LS wave activities in 1991/92 and in 2002.

While the EP flux analysis shows anomalous wave activity in the year after the eruption on a seasonal mean time frame, more can be learned about the nature of the troposphere-stratosphere coupling associated with the SWEs (Table 3) by investigating the temporal development of anomalous vertical wave propagation on a daily basis and as a function of pressure, represented by anomalies of the zonal mean eddy heat flux as a proxy for $F_{z}$ (Fig. 9). Figure 9 vertically complements the 100-hPa anomalous heat flux time series in Fig. 5a, extending the analysis of SWEs to the whole tropospherestratosphere system. Note that when the zonal mean daily eddy heat flux is time averaged, it contains both the stationary and transient components. Figure 9 demonstrates that the majority of the tropospheric and stratospheric wave activity events were connected and occurred in close temporal proximity. Most SWEs had their direct origin in the troposphere (Fig. 9, arrows). In some cases, the SWEs resulted from a stratospheric anomaly propagating downward (Table 3, STRAT), as on 21 March 1992, 4 September 1992, 1 October 1992, and 8 October 1992. These stratospheric anomalies were usually caused by a preceding upward propagating tropospheric anomaly. Shortly prior to final stratospheric warmings, LS eddy heat fluxes occur as a consequence of the reorganization of the stratospheric flow (e.g., Rao and Bonatti 1981). This signal usually propagates down to the troposphere (Thompson et al. 2005), which can also be seen for the two final warmings on 17 November 1991 and 15 November 1992 (cf. Table 3).

\section{d. Potential causes of the anomalous tropospheric wave activity}

The September 1991-November 1992 period coincided with one of the most pronounced negative SAM anomalies in the period 1979-2007 and an extended ENSO warm phase (Fig. 10). As Fig. 10 shows, there are many years when $F_{z}$ is in antiphase with the SAM. Evaluating three-monthly averages of $F_{z}$ and the SAM indicates that this relationship results from negative correlations during fall (MAM) and spring (SON) $\left(r_{\mathrm{MAM}}=-0.28\right.$ and $r_{\mathrm{SON}}=-0.37$, respectively). These relatively weak correlations are due to subperiods for which no correlation could be found, probably partly because of NNR data uncertainty in the 1980s (cf. section 3a). Much higher correlation coefficients are obtained, for instance, for $1985-2000\left(r_{\mathrm{MAM}}=-0.58\right.$ and $\left.r_{\mathrm{SON}}=-0.55\right)$. Since a large part of the anomalous LS planetary wave activity originated from the troposphere (see previous sections), the correlations indicate that the LS wave activity was 


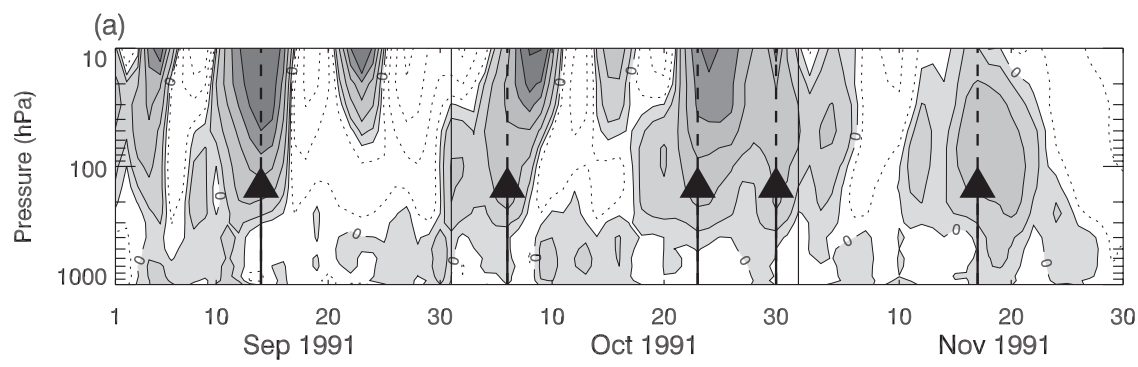

(b)

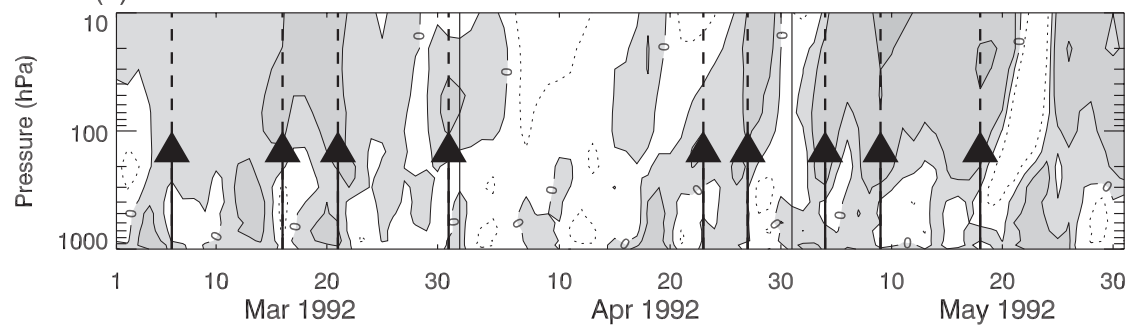

(c)

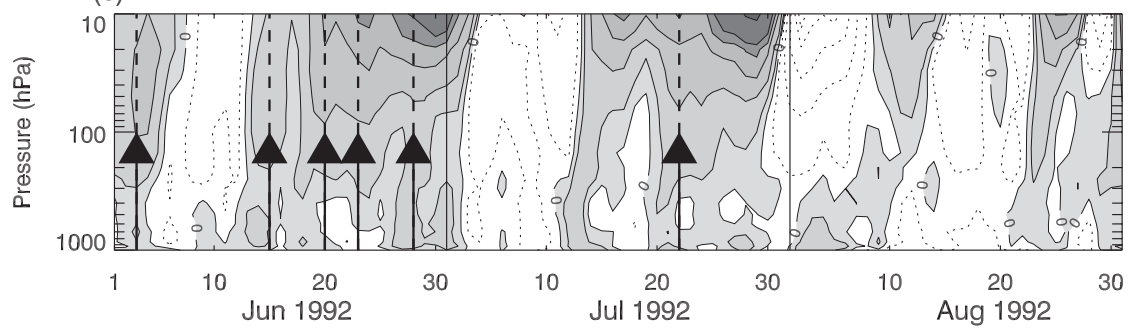

(d)

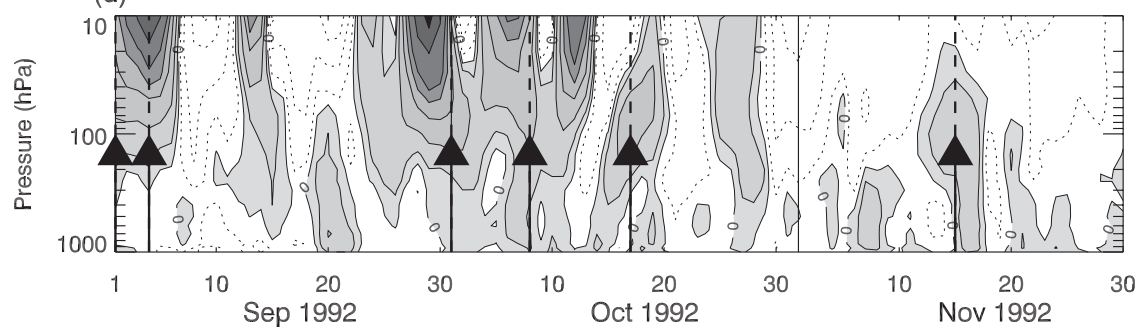

FIG. 9. Daily departures of $\left[v^{*} T^{*}\right]\left(\mathrm{K} \mathrm{m} \mathrm{s}^{-1}\right)$ from the 1979-2007 mean from September 1991 to November 1992 , averaged over $45^{\circ}-75^{\circ} \mathrm{S}$, as a function of pressure. The black arrows indicate the peaks of the SWEs listed in Table 3. The sign of the daily eddy heat flux has been reversed such that positive anomalies correspond to an increase in poleward eddy heat flux. In contrast to Fig. 5a, the unsmoothed data are shown. Positive contours are 5, 15, 30, 45, 60, 100, 150, and $200 \mathrm{~K} \mathrm{~m} \mathrm{~s}^{-1}$. (a) SON 1991, (b) MAM 1992, (c) JJA 1992, and (d) SON 1992.

at least partly associated with tropospheric circulation characteristics typical of the negative phase of the SAM, particularly during SON 1991 and MAM 1992.

One typical manifestation of the SAM is a higher frequency of wave breaking and blocking events in the east-central Indian Ocean and the New Zealand area/ southwestern Pacific region during austral winter during negative index conditions (Berrisford et al. 2007). Another preferred blocking region is in the southeastern Pacific (e.g., Trenberth and Mo 1985). It has been associated with enhanced blocking frequencies in the
ENSO warm phase year-round (Renwick 1998; Renwick and Revell 1999). The ENSO warm phase is also connected to increased blocking frequencies over the southwestern Pacific during spring and summer (Renwick 1998).

As explained in the introduction, blocking can significantly influence the stratospheric circulation in the case that planetary waves vertically propagate to stratospheric levels from the tropospheric anomaly. Blocking constitutes the most prominent group among quasistationary tropospheric flow patterns. Hence, we suspect 


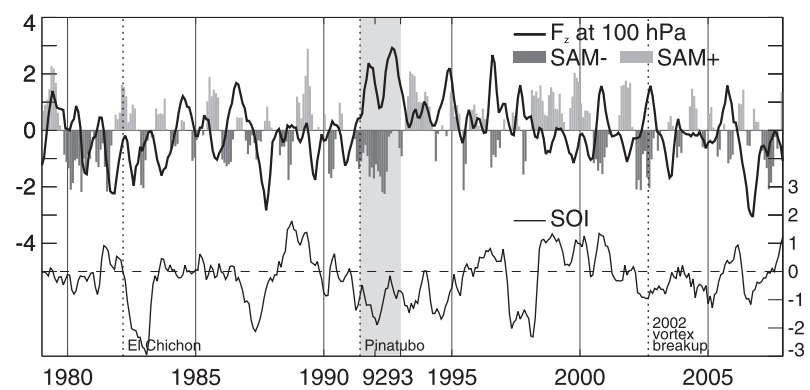

FIG. 10. Temporal evolution of the LS midlatitude $F_{z}\left(45^{\circ}-75^{\circ} \mathrm{S}\right.$, $100 \mathrm{hPa}$ ) (black line) and the SAM index at $700 \mathrm{hPa}$ (SAM negative phase: dark gray shading; SAM positive phase: light gray shading). Additionally, the Southern Oscillation index (SOI) is indicated at the bottom (thin gray line); $F_{z}$ is as in Fig. 4. All series have been normalized by one standard deviation and smoothed using a three-monthly running average. For sources of SAM and SOI data, see Table 1.

that the enhanced stationary wave activity in 1991/92 in the seasonal means (section 4c) and ultimately the increased stratospheric residual circulation (section $4 \mathrm{~b}$ ) were at least partly associated with an increased frequency of blocking episodes and related vertical wave propagation.

To analyze whether the post-Pinatubo period was in fact peculiar in terms of atmospheric blocking, we have calculated the percentage frequency of blocked days as a function of longitude applying the SH blocking index by Tibaldi et al. (1994) in a slightly modified form. Since blocking systems exhibit their maximum amplitude at the tropopause level (Schwierz et al. 2004), we have calculated the index at $300 \mathrm{hPa}$. Hereby, potential relationships of individual blocking events with the SWEs (Table 3) can be more easily diagnosed as the anomalies at 300 and $100 \mathrm{hPa}$ occur in close temporal proximity (see discussion below). Additionally, we missed some high-latitude blocking when using the standard formulation. Therefore, we have computed the geopotential height gradients over four instead of three latitude intervals-that is, applying $\phi_{N}=35^{\circ} \mathrm{S}+\Delta, \phi_{0}=50^{\circ} \mathrm{S}+$ $\Delta, \phi_{S}=65^{\circ} \mathrm{S}+\Delta$ as in Tibaldi et al. (1994), but $\Delta=-10^{\circ}$, $-5^{\circ}, 0^{\circ}, 5^{\circ}$ instead of $\Delta=-5^{\circ}, 0^{\circ}, 5^{\circ}$.

The results of the blocking index calculation for 19792007 and 1991/92 are shown in Fig. 11 for those seasons
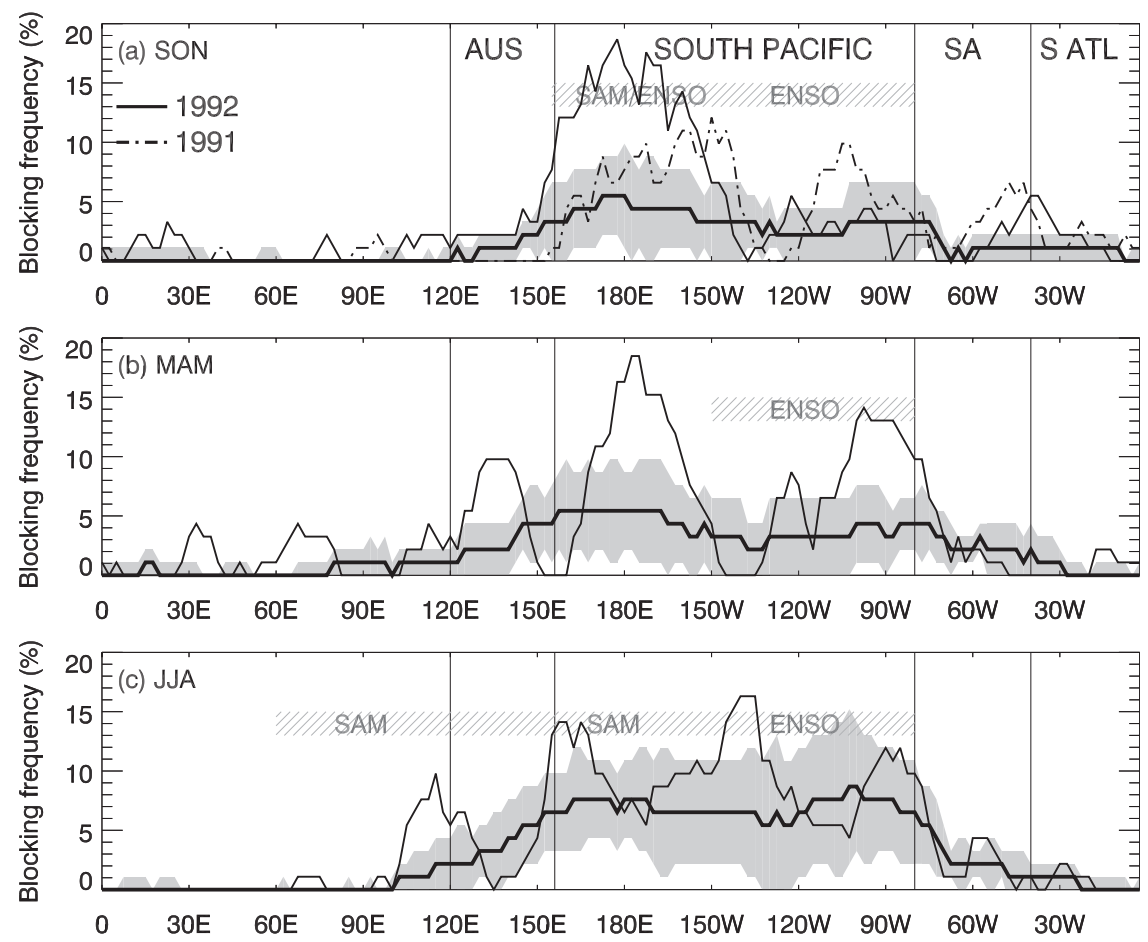

FIG. 11. Percentage frequency of blocked days in the $\mathrm{SH}$ at $300 \mathrm{hPa}$ as a function of longitude. Mean for 1979-2007 (thick black line), interannual variability (gray shading), and 1991/92 seasonal frequency (thin black line). (a) SON including seasonal frequencies of 1991 and 1992 , (b) MAM, and (c) JJA. Preferred blocking regions are indicated by vertical lines and denote the Australian (AUS), the South Pacific (SOUTH PACIFIC), South America (SA), and the South Atlantic (S ATL) regions. Known regional relationships of blocking frequency and $\mathrm{SAM} / \mathrm{ENSO}$ are shown in horizontal gray bars. 

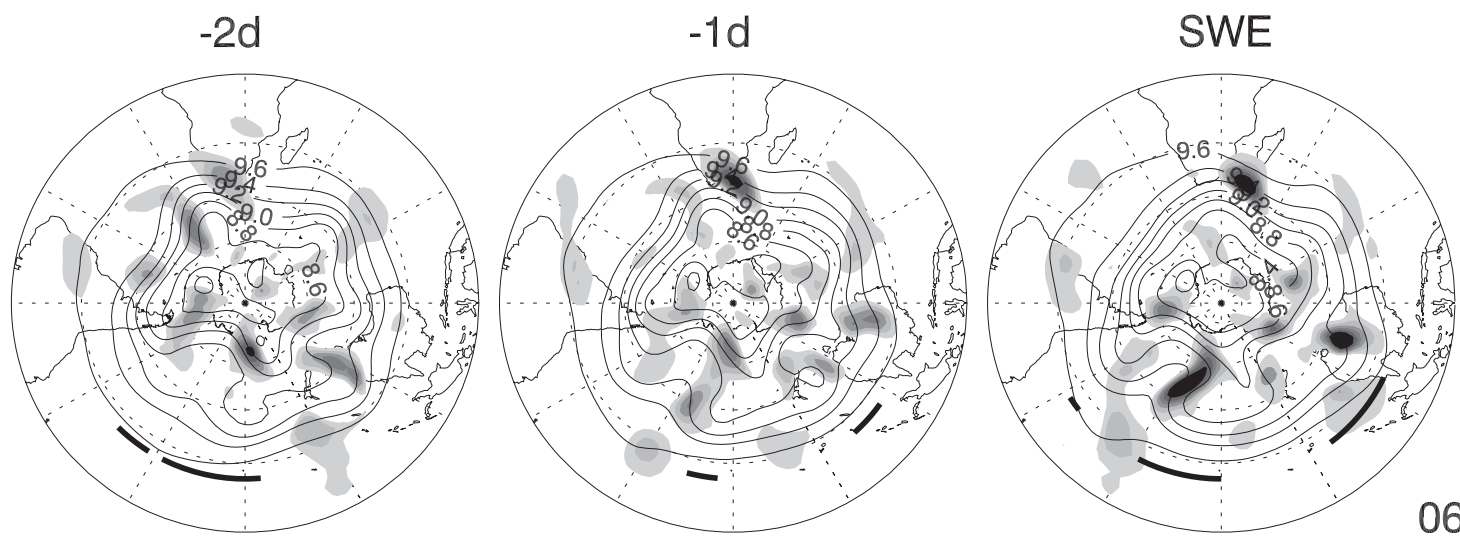

06/23/1992

FIG. 12. Relationship between geopotential height field (gpkm) at $300 \mathrm{hPa}$, anomalous eddy heat flux $-\Delta\left(v^{*} T^{*}\right)(1991 / 92-1979$ 2007), and blocking index preceding the stratospheric wave event on 23 Jun 1992 (cf. Table 3). The geopotential height contour interval is $0.2 \mathrm{gpkm}$, the eddy heat flux anomalies are indicated by the gray shading $\left(10,30,50,70\right.$, and $\left.90 \mathrm{~K} \mathrm{~m} \mathrm{~s} \mathrm{~s}^{-1}\right)$, and longitudes at which the blocking index is positive are denoted by thick black lines at $15^{\circ} \mathrm{S}$. (left) 2 days before the SWE, (middle) 1 day before the SWE, and (right) day of the SWE. The perpendicular longitudes are the $30^{\circ} \mathrm{E}$ and $150^{\circ} \mathrm{W}$ meridians. Latitudes are gridded at $20^{\circ}$ intervals from the equator.

in which planetary waves may propagate vertically into the stratosphere. The seasonality of the blocking frequency agrees well with the results by Tibaldi et al. (1994). Extremely high blocking frequencies occurred in 1991/92 in the preferred blocking regions. During SON 1991, the blocking frequency was more than twofold the LTM over the central South Pacific and up to a factor of 2 higher in the southeastern Pacific (Fig. 11a). Similarly, during MAM 1992 the blocking frequency was significantly enhanced at many longitudes, particularly over Australia, the southwestern Pacific, and the southeastern Pacific (Fig. 11b). During JJA 1992 largely enhanced blocking frequencies occurred over the southeastern Indian Ocean, the southwestern and central Pacific, and the southeastern Pacific/South America (Fig. 11c). Again during spring 1992, a very pronounced maximum emerged over the southwestern Pacific with values of up to 4 times the LTM. The enhanced blocking frequencies over regions susceptible to SAM and ENSO flow variability suggest that the SH tropospheric flow in 1991/92 largely reflected the negative SAM index conditions and was significantly influenced by ENSO.

Finally, we try to relate the SWEs (Table 3) with specific preceding synoptic tropospheric weather patterns on a case-by-case basis. For this purpose, we present the upper tropospheric flow, represented by $300-\mathrm{hPa}$ geopotential height and the associated poleward eddy heat flux $v^{*} T^{*}$ as geographical distributions at the time of the SWE and for the two preceding days (Figs. 12 and A1-A4). Blocking has been defined to have occurred preceding a SWE in Table 3 only if this blocking locally coincided with large anomalous poleward heat fluxes.
The tropospheric synoptic patterns preceding the SWEs are all associated with large quasi-stationary departures from the zonal state (Figs. 12 and A1-A4). As is exemplarily shown for the SWE on 23 June 1992 (Fig. 12), anomalous poleward heat fluxes typically appear on the flanking sides of pronounced high or low pressure systems where polar air is advected northward or midlatitude air transported southward. Fifteen out of 20 SWEs in Table 3 (excluding SFWs and STRAT events) are associated with blocking patterns emphasizing their importance for $\mathrm{SH}$ stratospheric variability in the postPinatubo period. By grouping the blocking anticyclones according to their location we find that during May and June 1992 there is a significant preference for blocking over the southeastern Pacific (Table 3), indicating that during these months the ENSO warm phase was largely responsible for preconditioning the tropospheric flow and hence for laying the foundation for vertical planetary wave propagation to the middle atmosphere and the strengthening of the Brewer-Dobson circulation. Our results are supported by a statistical analysis of NIWA extreme total ozone values (H. Rieder et al. 2011, unpublished manuscript), which shows that ENSO significantly influences column ozone at midlatitudes in both hemispheres and indicates that ozone transport from the tropics to the extratropics is enhanced during the ENSO warm phase compared to the cold phase.

\section{Concluding remarks}

While large total ozone decreases occurred in the $\mathrm{NH}$ extratropics for several years following the eruption of Mt. Pinatubo in 1991 that are generally considered to have been caused by the eruption, no comparable ozone 
decreases were observed at SH midlatitudes. In a multiple linear regression of column ozone against natural and anthropogenic forcing factors and evaluating NCEP-NCAR reanalysis data, we have investigated the cause(s) for this apparent missing decrease at $\mathrm{SH}$ midlatitudes. This study shows that $\mathrm{SH}$ tropospheric midlatitude stationary wave activity was unusually large during austral spring 1991 and from fall to spring 1992. These waves propagated vertically into the stratosphere and were mainly responsible for an increased downwelling at $\mathrm{SH}$ midlatitudes. We suggest that this anomalous wave activity worked together with aerosol heating, predominantly at low latitudes, in causing a largely enhanced Brewer-Dobson circulation in the year after the eruption. We argue that it is this increase in the stratospheric residual circulation that was responsible for transporting more ozone from the production region in the tropics to middle and high latitudes, overcompensating the chemical ozone loss and resulting in the observed positive column ozone anomaly between austral spring 1991 and the middle of 1992. Thus, our results indicate that the effect of the anomalous wave activity was to shift the onset of evident chemical ozone loss to the middle of 1992 and to reduce the overall strength of the volcanic ozone signal.

The tropospheric circulation in 1991/92 was characterized by a pronounced negative phase of the SAM and an ENSO warm phase. We suggest that the coincidence of these two oscillation patterns was associated with a preference of the midlatitude tropospheric flow to form quasi-stationary patterns including atmospheric blocking, which is known to precede vertical wave propagation associated with stratospheric warmings in both hemispheres. SH blocking activity in 1991/92 was significantly enhanced in regions typical for blocking formation. In particular, the preferred blocking location over the southeastern Pacific during the austral winter of 1992 points to a major influence of the ENSO warm phase on wave activity during this season.

It may be argued that the volcanic eruption itself contributed to the anomalous tropospheric circulation in the post-Pinatubo period. The volcanic aerosolinduced low and midlatitude cooling was larger than that at high latitudes (Robock 2002), which would act to reduce meridional temperature gradients and hence result in a reduced strength of the SAM. The same argument has already been put forward in connection with the eruption of Agung in 1963, after which a pronounced negative anomaly in the SAM was observed as well (Marshall 2003), and might also apply to the eruption of El Chichón in 1982, when the SAM dropped from the positive to the negative phase within half a year after the eruption (Fig. 10). Support for a negative SAM response to large volcanic eruptions also comes from a study by Roscoe and Haigh (2007), who found in a multiple linear regression analysis of the SAM for 1957-2005 a negative response to volcanic forcing. Interestingly, in the $\mathrm{NH}$, the correlation of the northern annular mode (NAM) with volcanic aerosol is positive (Haigh and Roscoe 2006). However, current global climate models have not been able to reproduce a negative SAM response to the Pinatubo eruption (Robock et al. 2007; Karpechko et al. 2010), leaving this issue unresolved.

While we have been able to explain why no reduction in total ozone columns was observed at SH midlatitudes after the Pinatubo eruption, the study raises new questions concerning the link between SAM and ENSO regarding their roles for vertical wave propagation into the middle atmosphere, and why the Northern and Southern Hemisphere circulations responded differently to the volcanic aerosol. Further insight into the roles of SAM and ENSO onto tropospheric wave activity and vertical propagation might, for instance, be gained by comparison with the dynamical situation in 2002 when similar tropospheric circulation patterns prevailed as in 1991/92 (i.e., a negative SAM and an ENSO warm phase). In addition, evaluating modeling results (e.g., from global coupled chemistry-climate models) with realistic aerosol forcing and prescribed temporally varying SSTs may help to further resolve remaining issues.

Acknowledgments. Christina Schnadt Poberaj was supported by a research grant of MeteoSwiss (Global Atmosphere Watch, GAW, Switzerland). We thank Greg Bodeker for processing and providing us the NIWA data, and the Alfred-Wegener Institut für Polar- und Meeresforschung (AWI) for making the midlatitude EP flux data available on the internet. We also thank Martin Dameris and Olivia Martius for reading draft versions of the manuscript and for valuable discussions. Finally, we are grateful to the two anonymous reviewers for their constructive comments. NCEP Reanalysis data have been provided by the NOAA/OAR/ESRL PSD, Boulder, Colorado, USA, from their Web site at http://www.esrl. noaa.gov/psd/. The EESC data have been obtained from the Goddard automailer at http://acdb-ext.gsfc.nasa.gov/ Data_services/automailer/.

\section{APPENDIX}

\section{Relationship among Geopotential, Anomalous Eddy Heat Flux, and Blocking for all SWEs}

Figures A1-A4 show the other SWE cases listed in Table 3 (except STRAT and SFW) and their respective preceding synoptic tropospheric weather patterns, 

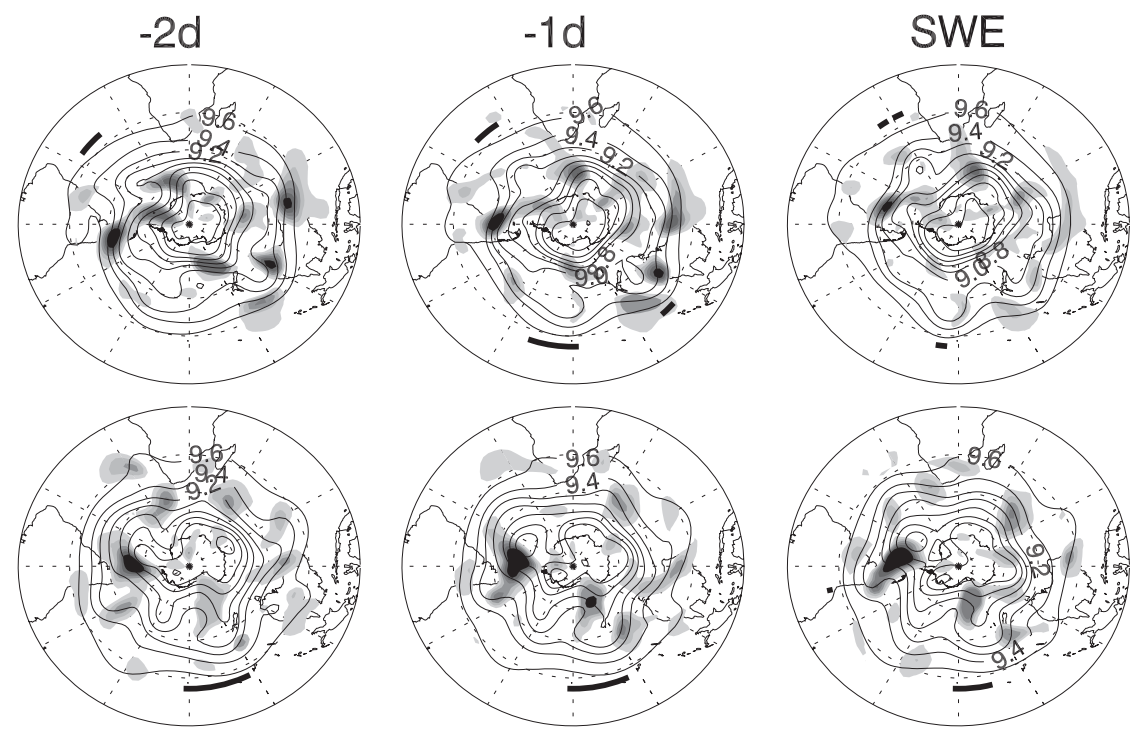

09/14/1991
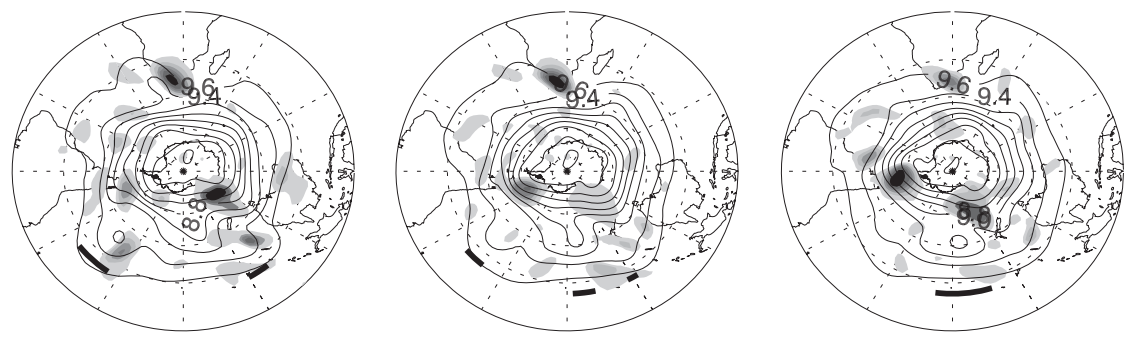

$10 / 06 / 1991$
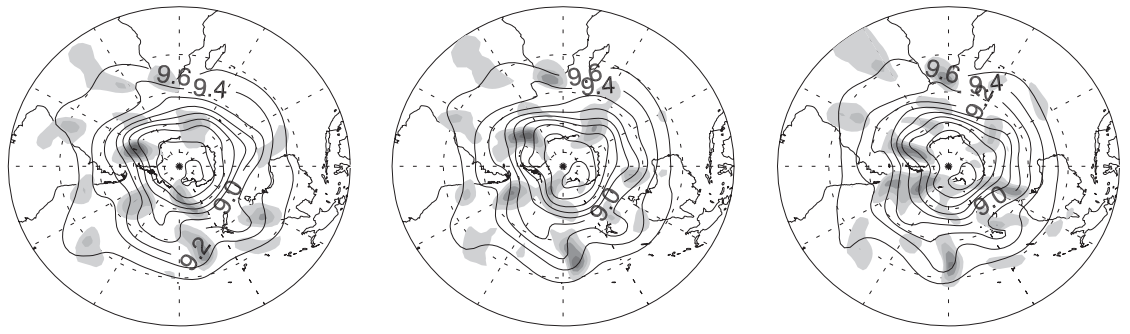

$10 / 23 / 1991$
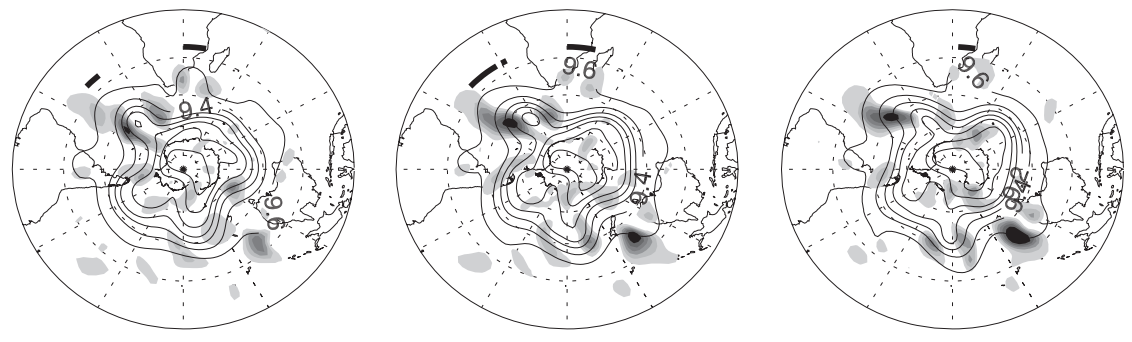

$10 / 30 / 1991$
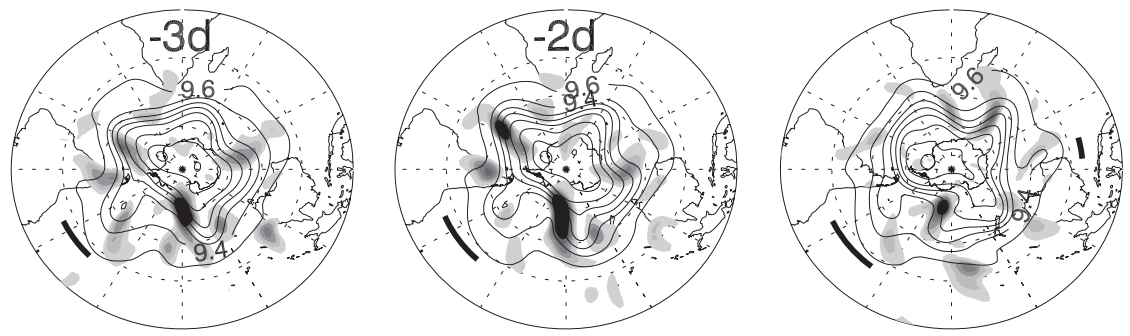

03/06/1992

FIG. A1. (a) As in Fig. 12, but for SWEs on 14 Sep, 6 Oct, 23 Oct, and 30 Oct 1991, and 6 Mar and 16 Mar 1992. 

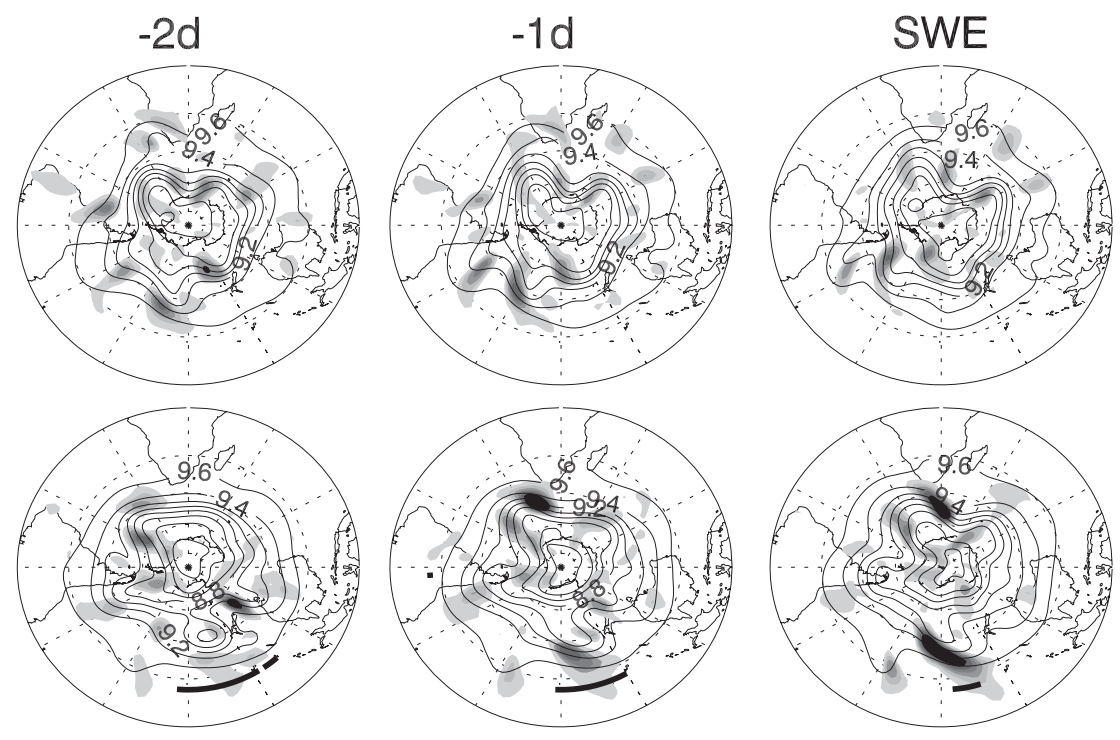

03/31/1992
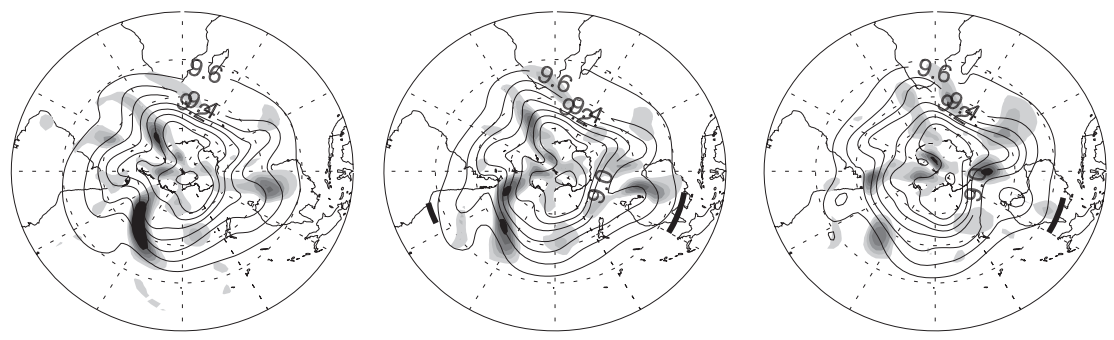

04/23/1992
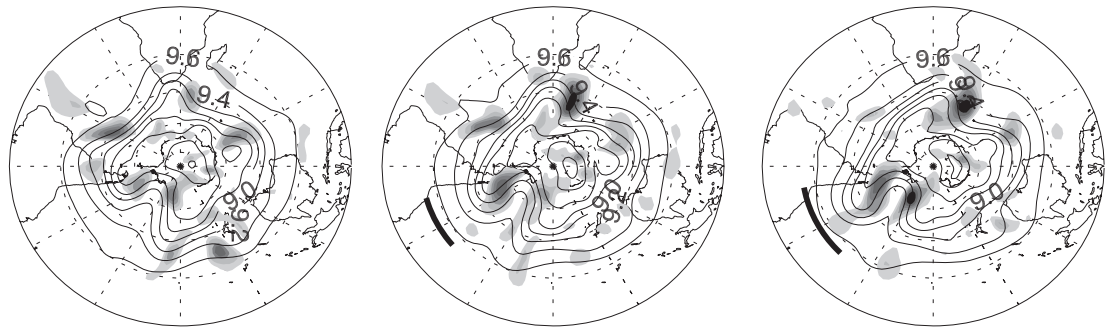

04/27/1992
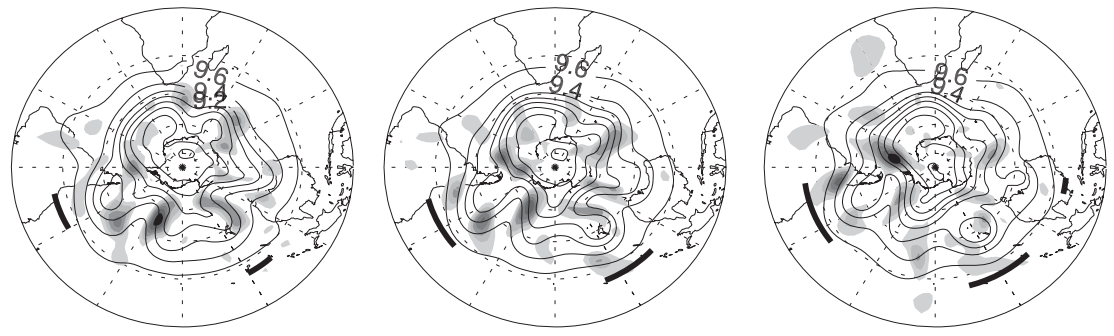

05/04/1992
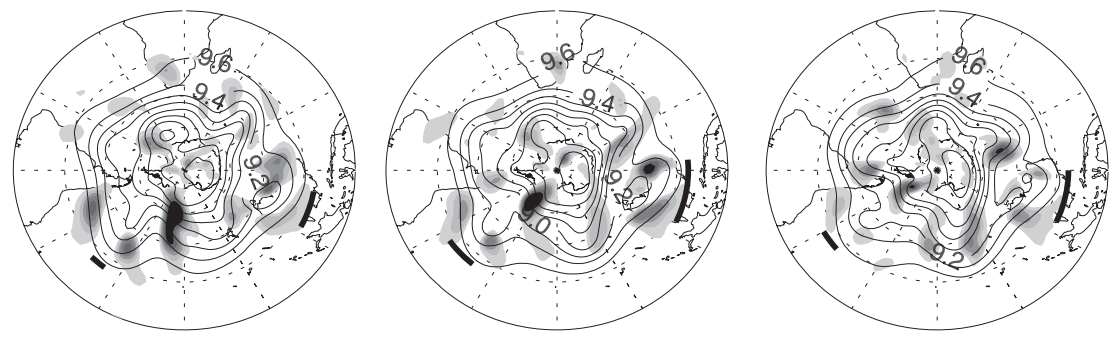

05/09/1992

FIG. A2. As in Fig. 12, but for SWEs on 31 Mar, 23 Apr, 27 Apr, 4 May, 9 May, and 18 May 1992. 

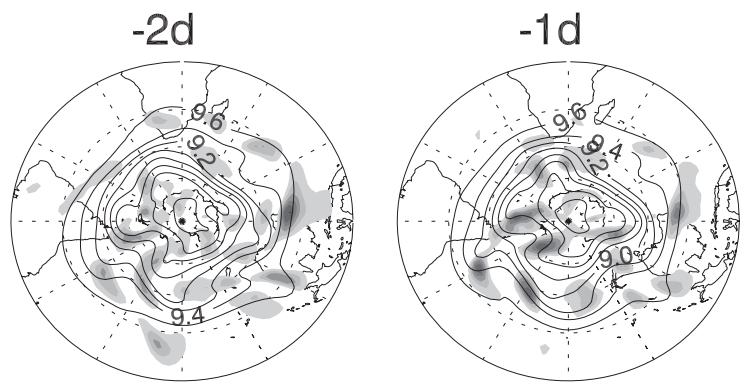

SWE
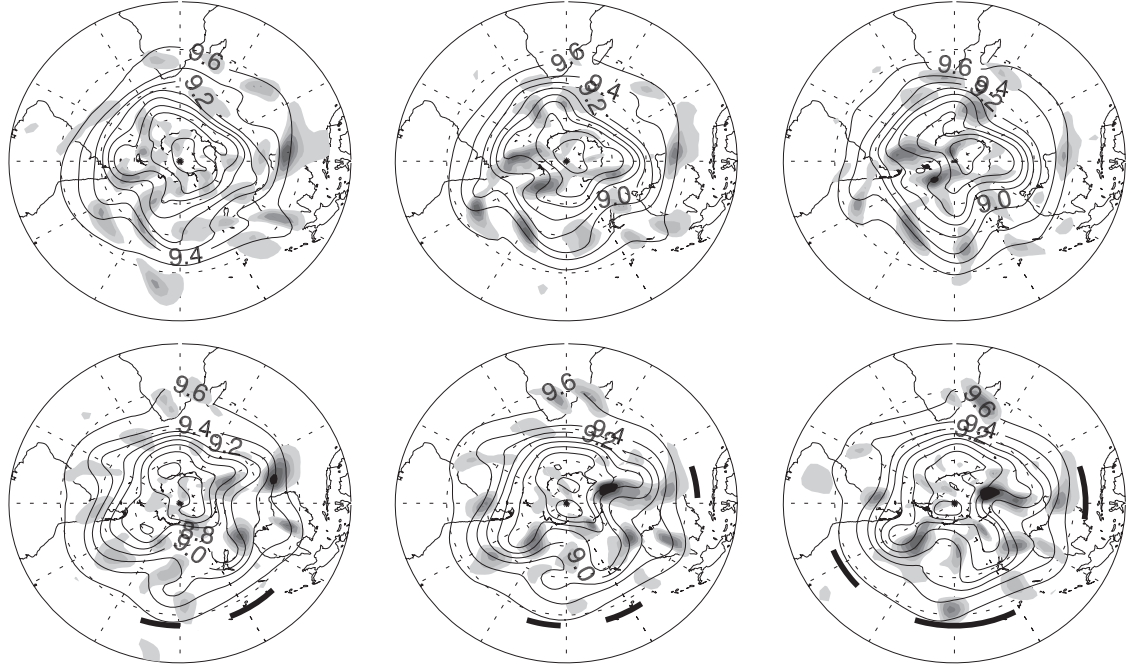

06/03/1992
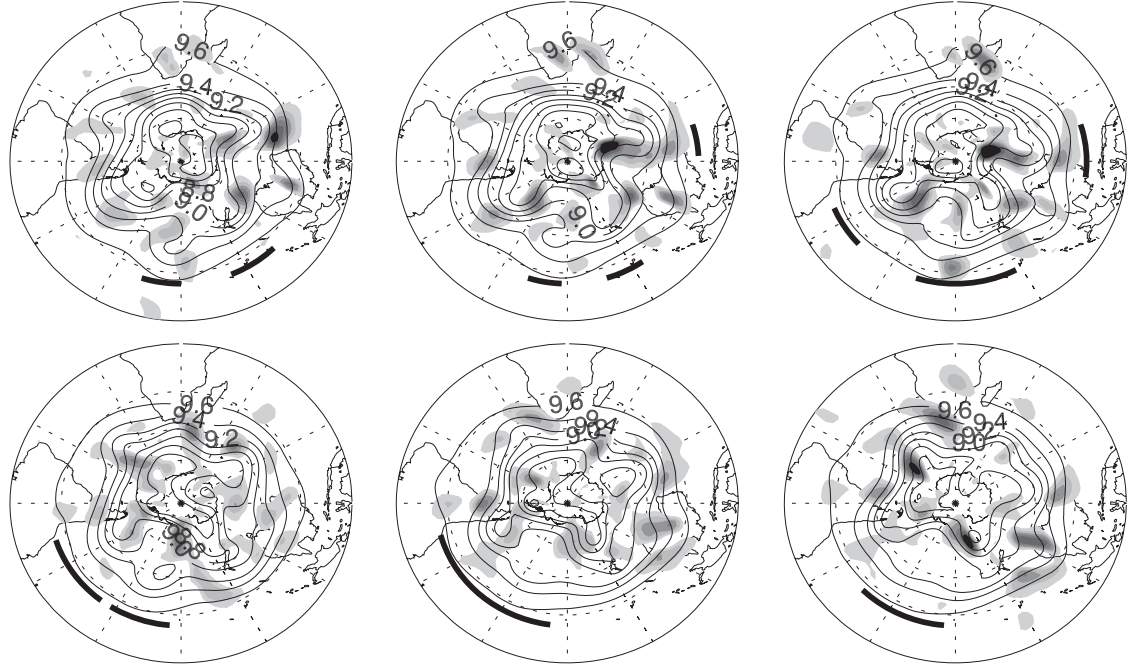

06/15/1992
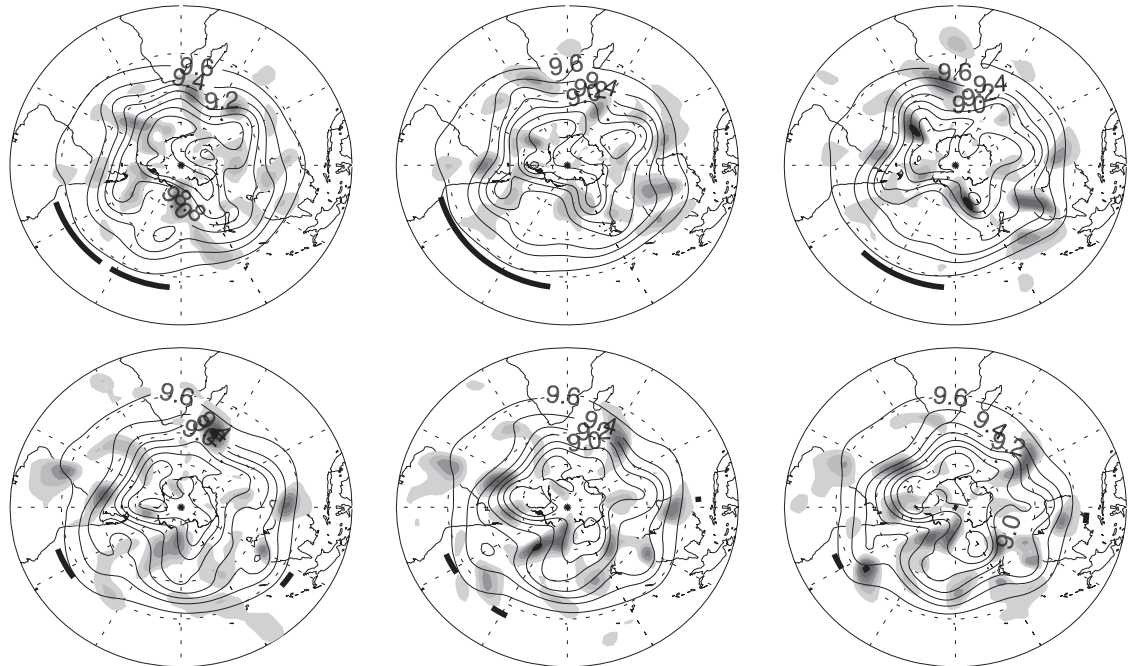

$06 / 20 / 1992$
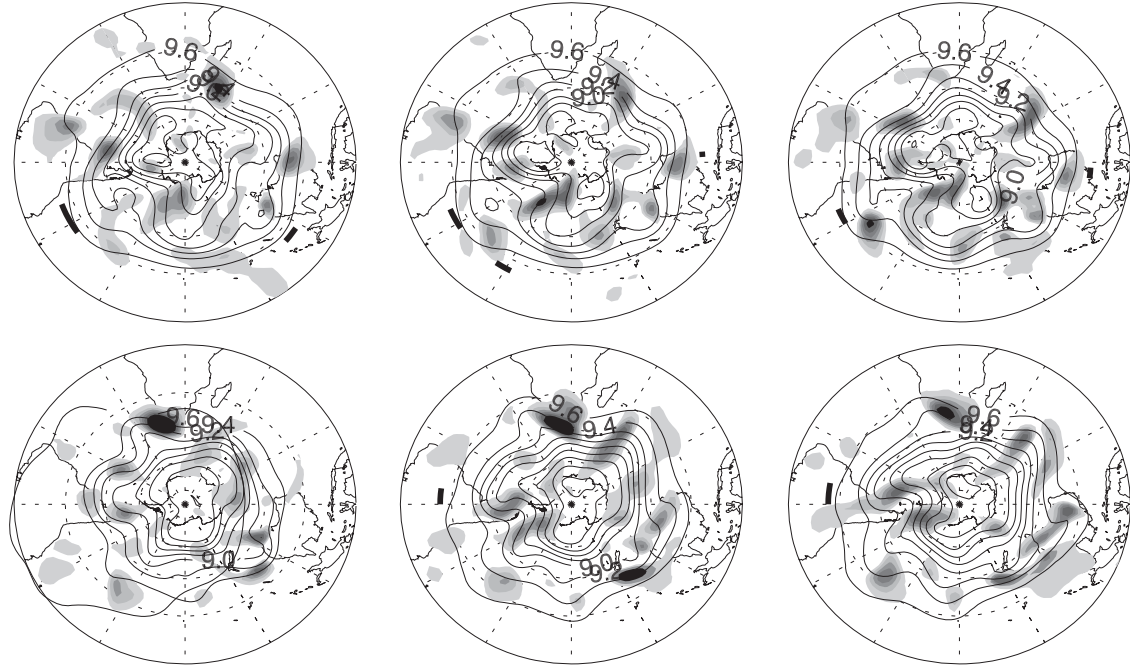

06/28/1992
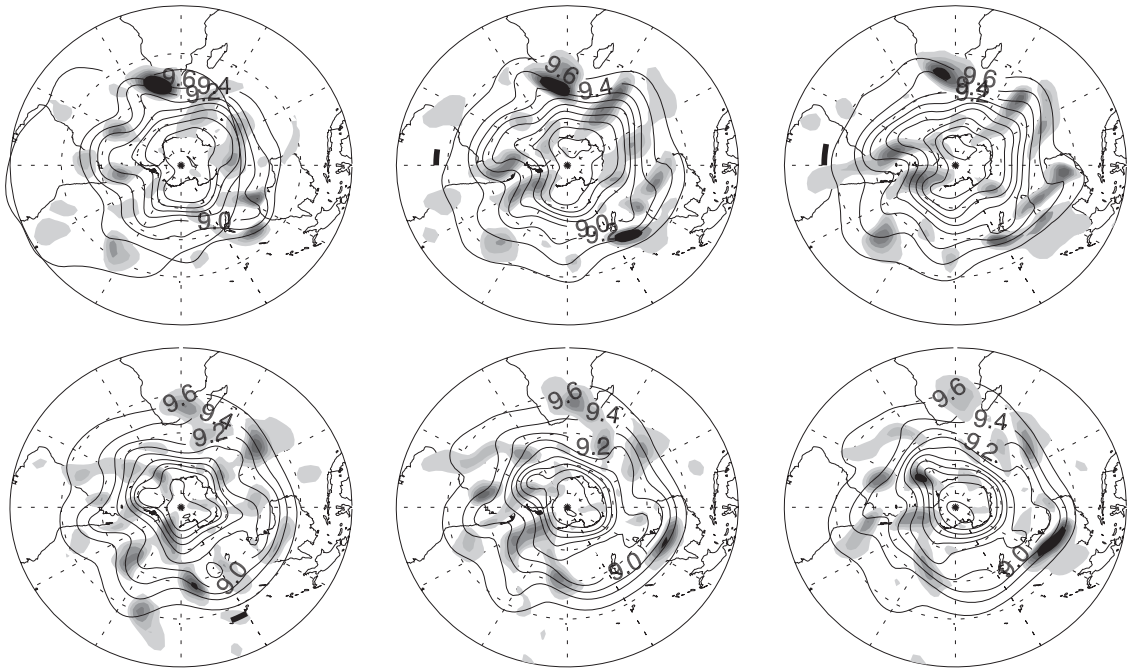

07/22/1992

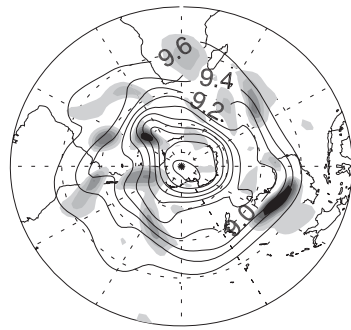

09/01/1992

FIG. A3. As in Fig. 12, but for SWEs on 3 Jun, 15 Jun, 20 Jun, 28 Jun, 22 Jul, and 1 Sep 1992. 

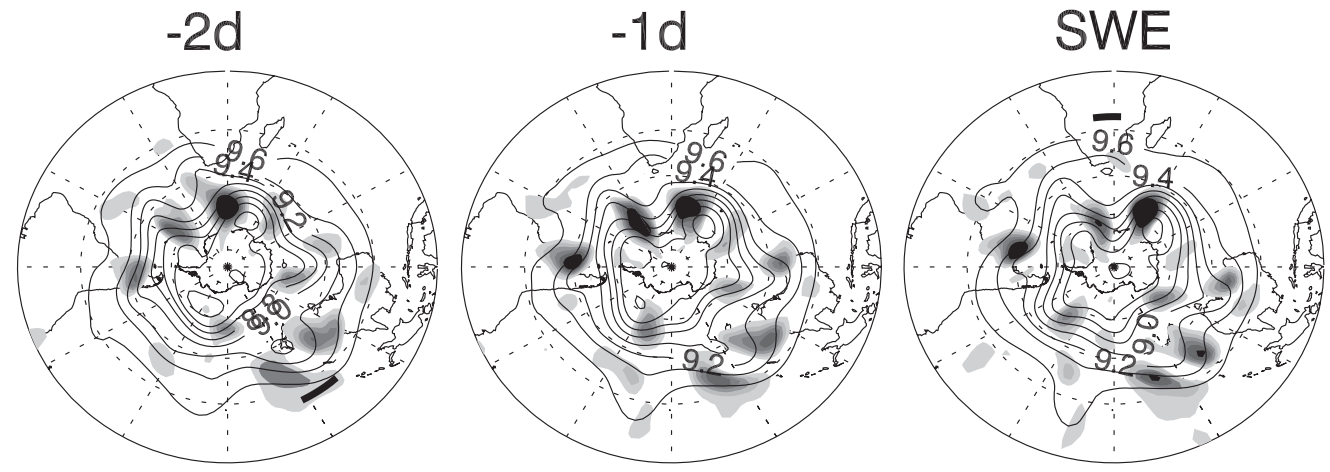

$10 / 17 / 1992$

FIG. A4. As in Fig. 12, but for SWE on 17 Oct 1992.

including the 300-hPa geopotential height and the associated poleward eddy heat flux. See the text, Table 3, and Fig. 12 for more details.

\section{REFERENCES}

Andrews, D. G., and M. E. McIntyre, 1976: Planetary waves in horizontal and vertical shear: The generalized Eliassen-Palm relation and the mean zonal acceleration. J. Atmos. Sci., 33, 2031-2048.

—_, and —_, 1978: Generalized Eliassen-Palm and CharneyDrazin theorems for waves on axisymmetric mean flows in compressible atmospheres. J. Atmos. Sci., 35, 175-185.

— , J. R. Holton, and C. B. Leovy, 1987: Middle Atmosphere Dynamics. Academic Press, 489 pp.

Baldwin, M. P., and Coauthors, 2001: The quasi-biennial oscillation. Rev. Geophys., 39, 179-229.

Berrisford, P., B. J. Hoskins, and E. Tyrlis, 2007: Blocking and Rossby wave breaking on the dynamical tropopause in the Southern Hemisphere. J. Atmos. Sci., 64, 2881-2898.

Bhartia, P. K., C. G. Wellemeyer, S. L. Taylor, N. Nath, and A. Gopalan, 2004: Solar Backscatter Ultraviolet (SBUV) version 8 profile algorithm. Proc. 20th Quadrennial Ozone Symp., Kos, Greece, International Ozone Commission, 295-296.

Bodeker, G. E., J. C. Scott, K. Kreher, and R. L. McKenzie, 2001: Global ozone trends in potential vorticity coordinates using TOMS and GOME intercompared against the Dobson network: 1978-1998. J. Geophys. Res., 106, 23 029-23 042.

- H. Shiona, and H. Eskes, 2005: Indicators of Antarctic ozone depletion. Atmos. Chem. Phys., 5, 2603-2615.

— , H. Garny, D. Smale, M. Dameris, and R. Deckert, 2007: The 1985 Southern Hemisphere mid-latitude total column ozone anomaly. Atmos. Chem. Phys., 7, 5625-5637.

Bowman, K. P., 1989: Global patterns of the quasi-biennial oscillation in total ozone. J. Atmos. Sci., 46, 3328-3343.

Brunner, D., J. Staehelin, H. R. Künsch, and G. E. Bodeker, 2006a: A Kalman filter reconstruction of the vertical ozone distribution in an equivalent latitude-potential temperature framework from TOMS/GOME/SBUV total ozone observations. J. Geophys. Res., 111, D12308, doi:10.1029/2005JD006279.

, _ J. Maeder, I. Wohltmann, and G. Bodeker, 2006b: Variability and trends in total and vertically resolved stratospheric ozone based on the CATO ozone data set. Atmos. Chem. Phys., 6, 4985-5008.

Charney, J. G., and P. G. Drazin, 1961: Propagation of planetaryscale disturbances from the lower into the upper atmosphere. J. Geophys. Res., 66, 83-109.
Dhomse, S., M. Weber, I. Wohltmann, M. Rex, and J. P. Burrows, 2006: On the possible causes of recent increases in Northern Hemispheric total ozone from a statistical analysis of satellite data from 1979 to 2003. Atmos. Chem. Phys., 6, 11651180.

Dunkerton, T., C.-P. F. Hsu, and M. E. McIntyre, 1981: Some Eulerian and Lagrangian diagnostics for a model stratospheric warming. J. Atmos. Sci., 38, 819-844.

Dutton, E. G., and J. R. Christy, 1992: Solar radiative forcing at selected locations and evidence for global lower tropospheric cooling following the eruptions of El Chichón and Pinatubo. Geophys. Res. Lett., 19, 2313-2316.

Eliassen, A., and E. Palm, 1961: On the transfer of energy in stationary mountain waves. Geofys. Publ., 22, 1-23.

Fleming, E. L., C. H. Jackman, D. K. Weisenstein, and M. K. W. Ko, 2007: The impact of interannual variability on multidecadal total ozone simulations. J. Geophys. Res., 112, D10310, doi:10.1029/2006JD007953.

Fortuin, J. P. F., and H. Kelder, 1998: An ozone climatology based on ozonesonde and satellite measurements. J. Geophys. Res., 103, 31 709-31 734.

Fusco, A. C., and M. L. Salby, 1999: Interannual variations of total ozone and their relationship to variations of planetary wave activity. J. Climate, 12, 1619-1629.

Gleason, J. F., and Coauthors, 1993: Record low global ozone in 1992. Science, 260, 523-526.

Graf, H.-F., Q. Li, and M. A. Giorgetta, 2007: Volcanic effects on climate: Revisiting the mechanisms. Atmos. Chem. Phys., 7, 4503-4511.

Haigh, J. D., and H. K. Roscoe, 2006: Solar influences on polar modes of variability. Meteor. Z., 15, 371-378.

Hamilton, K., 1989: Effects of an imposed quasi-biennial oscillation in a comprehensive troposphere-stratospheremesosphere general circulation model. J. Atmos. Sci., 55, 2393-2418.

Harris, N. R. P., and Coauthors, 2008: Ozone trends at northern mid- and high latitudes-A European perspective. Ann. Geophys., 26, 1207-1220.

Hartmann, D. L., 1977: Stationary planetary waves in the Southern Hemisphere. J. Geophys. Res., 82, 4930-4934.

_ C. R. Mechoso, and K. Yamazaki, 1984: Observations of wave-mean flow interaction in the Southern Hemisphere. J. Atmos. Sci., 41, 351-362.

Hofmann, D. J., and Coauthors, 1994: Ozone loss in the lower stratosphere over the United States in 1992-1993: Evidence for heterogeneous chemistry on the Pinatubo aerosol. Geophys. Res. Lett., 21, 65-68. 
Holton, J. R., P. H. Haynes, M. E. McIntyre, A. R. Douglass, R. B. Rood, and L. Pfister, 1995: Stratosphere-troposphere exchange. Rev. Geophys., 33, 403-439.

Hurrell, J. W., H. van Loon, and D. J. Shear, 1998: The mean state of the troposphere. Meteorology of the Southern Hemisphere, Meteor. Monogr., No. 49, Amer. Meteor. Soc., 1-46.

Iwasaki, T., H. Hamada, and K. Miyazaki, 2009: Comparisons of Brewer-Dobson circulations diagnosed from reanalyses. J. Meteor. Soc. Japan, 87, 997-1006.

James, I. N., 1994: Introduction to Circulating Atmospheres. Cambridge University Press, $246 \mathrm{pp}$.

Kalnay, E., and Coauthors, 1996: The NCEP/NCAR 40-Year Reanalysis Project. Bull. Amer. Meteor. Soc., 77, 437-471.

Karoly, D. J., 1985: An atmospheric climatology of the southern hemisphere based on ten years of daily numerical analyses (1972-82). II: Standing wave climatology. Aust. Meteor. Mag., 33, 105-116.

1989: Southern Hemisphere circulation features associated with El Niño-Southern Oscillation events. J. Climate, 2, 12391252.

— D. G. Vincent, and J. M. Schrage, 1999: General circulation. Meteorology of the Southern Hemisphere, Meteor. Monogr., No. 49, Amer. Meteor. Soc., 47-85.

Karpechko, A. Y., N. P. Gillett, M. Dall'Amico, and L. J. Gray, 2010: Southern Hemisphere atmospheric circulation response to the El Chichón and Pinatubo eruptions in coupled climate models. Quart. J. Roy. Meteor. Soc., 136, 1813-1822.

Kerr, J. B., D. J. Wardle, and D. W. Tarasick, 1993: Record low ozone values over Canada in early 1993. Geophys. Res. Lett., 20, 1979-1982.

Kinne, S., O. B. Toon, and M. J. Prather, 1992: Buffering of stratospheric circulation by changing amounts of tropical ozone: A Pinatubo case study. Geophys. Res. Lett., 19, 1927-1930.

Kinnersley, J. S., and K. K. Tung, 1999: Modeling the global interannual variability of ozone due to the equatorial QBO and to extratropical planetary wave variability. J. Atmos. Sci., 55, 1417-1428.

Labitzke, K., and M. P. McCormick, 1992: Stratospheric temperature increases due to Pinatubo aerosols. Geophys. Res. Lett., 19, 207-210.

Lait, L. R., M. R. Schoeberl, and P. A. Newman, 1989: Quasibiennial modulation of the Antarctic ozone depletion. J. Geophys. Res., 94, 11 559-11 571.

Li, F., J. Austin, and J. Wilson, 2008: The strength of the BrewerDobson circulation in a changing climate: Coupled chemistryclimate model simulations. J. Climate, 21, 40-57.

, P. A. Newman, and R. S. Stolarski, 2010: Relationships between the Brewer-Dobson circulation and the southern annular mode during austral summer in coupled chemistryclimate model simulations. J. Geophys. Res., 115, D15106, doi:10.1029/2009JD012876.

Marshall, G. J., 2003: Trends in the southern annular mode from observations and reanalyses. J. Climate, 16, 4134-4143.

Martius, O., L. M. Polvani, and H. C. Davies, 2009: Blocking precursors to stratospheric sudden warming events. Geophys. Res. Lett., 36, L14806, doi:10.1029/2009GL038776.

Minnis, P., E. F. Harrison, L. L. Stowe, G. G. Gibson, F. M. Denn, D. R. Doelling, and W. L. Smith Jr., 1993: Radiative climate forcing by the Mount Pinatubo eruption. Science, 259, 14111415.

Newman, P. A., and E. R. Nash, 2005: The unusual Southern Hemisphere stratosphere winter of 2002. J. Atmos. Sci., 62, 614-628.
,-- , S. R. Kawa, S. A. Montzka, and S. M. Schauffler, 2006: When will the Antarctic ozone hole recover? Geophys. Res. Lett., 33, L12814, doi:10.1029/2005GL025232.

Nigam, S., and E. DeWeaver, 2003: Stationary waves (orographic and thermally forced). Encyclopedia of Atmospheric Sciences, J. R. Holton, J. A. Pyle, and J. A. Curry, Eds., Academic Press, 2121-2137.

Nishii, K., and H. Nakamura, 2004: Lower-stratospheric Rossby wave trains in the Southern Hemisphere: A case-study for late winter of 1997. Quart. J. Roy. Meteor. Soc., 130, 325-345.

Oman, L., D. W. Waugh, S. Pawson, R. S. Stolarski, and P. A. Newman, 2009: On the influence of anthropogenic forcings on changes in the stratospheric mean age. J. Geophys. Res., 114, D03105, doi:10.1029/2008JD010378.

Pitari, G., and E. Mancini, 2002: Short-term climatic impact of the 1991 volcanic eruption of Mt. Pinatubo and effects on atmospheric tracers. Nat. Hazards Earth Syst. Sci., 2, 91-108.

Polvani, L. M., D. W. Waugh, G. J. P. Correa, and S.-W. Son, 2011: Stratospheric ozone depletion: The main driver of twentiethcentury atmospheric circulation changes in the Southern Hemisphere. J. Climate, 24, 795-812.

Quintanar, A. I., and C. R. Mechoso, 1995: Quasi-stationary waves in the Southern Hemisphere. Part I: Observational data. J. Climate, 8, 2659-2672.

Randel, W. J., 1988: The seasonal evolution of planetary waves in the Southern Hemisphere stratosphere and troposphere. Quart. J. Roy. Meteor. Soc., 114, 1385-1409.

— data by singular-value decomposition. J. Atmos. Sci., 53, 25462559.

,-- J. M. Russell III, J. W. Waters, and L. Froidevaux, 1995: Ozone and temperature changes in the stratosphere following the eruption of Mount Pinatubo. J. Geophys. Res., 100, $16753-16764$.

- , - and R. Stolarski, 2002: Changes in column ozone correlated with the stratospheric EP flux. J. Meteor. Soc. Japan, 80, 849-862.

Rao, V. B., and J. P. Bonatti, 1981: On the efficiency of meridional eddy transport processes during the major stratospheric warming of January 1977. Tellus, 33, 61-67.

— J. P. R. Fernandez, and S. H. Franchito, 2004: Quasi-stationary waves in the Southern Hemisphere during El Niño and La Niña events. Ann. Geophys., 22, 789-806.

Renwick, J. A., 1998: ENSO-related variability in the frequency of South Pacific blocking. Mon. Wea. Rev., 126, 3117-3123.

— , and M. J. Revell, 1999: Blocking over the South Pacific and Rossby wave propagation. Mon. Wea. Rev., 127, 2233-2247.

Rex, D. F., 1950: Blocking action in the middle troposphere and its effect upon regional climate. I: An aerological study of blocking. Tellus, 2, 196-211.

Rex, M., R. J. Salawitch, P. von der Gathen, N. R. P. Harris, M. P. Chipperfield, and B. Naujokat, 2004: Arctic ozone loss and climate change. Geophys. Res. Lett., 31, L04116, doi:10.1029/ 2003 GL018844.

Robock, A., 2002: The climatic aftermath. Science, 295, 1242 1244.

—, T. Adams, M. Moore, L. Oman, and G. Stenchikov, 2007: Southern Hemisphere atmospheric circulation effects of the 1991 Mount Pinatubo eruption. Geophys. Res. Lett., 34, L23710, doi:10.1029/2007GL031403.

Roscoe, H. K., and J. D. Haigh, 2007: Influences of ozone depletion, the solar cycle and the QBO on the southern annular mode. Quart. J. Roy. Meteor. Soc., 133, 1855-1864. 
Rosenlof, K. H., 1995: Seasonal cycle of the residual mean meridional circulation in the stratosphere. J. Geophys. Res., 100, 5173-5191.

Rosier, S. M., and B. N. Lawrence, 1999: The January 1992 stratospheric sudden warming: A role for tropical inertial instability? Quart. J. Roy. Meteor. Soc., 125, 2575-2596.

,,-- D. G. Andrews, and F. W. Taylor, 1994: Dynamical evolution of the northern stratosphere in early winter 1991/92, as observed by the Improved Stratospheric and Mesospheric Sounder. J. Atmos. Sci., 51, 2783-2799.

Salby, M. L., 2008: Involvement of the Brewer-Dobson circulation in changes of stratospheric temperature and ozone. Dyn. Atmos. Oceans, 44, 143-164.

Schwierz, C., M. Croci-Maspoli, and H. C. Davies, 2004: Perspicacious indicators of atmospheric blocking. Geophys. Res. Lett., 31, L06125, doi:10.1029/2003GL019341.

Shepherd, T. G., 2007: Transport in the middle atmosphere. J. Meteor. Soc. Japan, 85B, 165-191.

Solomon, S., 1999: Stratospheric ozone depletion: A review of concepts and history. Rev. Geophys., 37, 275-316.

Stenchikov, G., A. Robock, V. Ramaswamy, M. D. Schwarzkopf, K. Hamilton, and S. Ramachandran, 2002: Arctic Oscillation response to the 1991 Mount Pinatubo eruption: Effects of volcanic aerosols and ozone depletion. J. Geophys. Res., 107, 4803, doi:10.1029/2002JD002090.

Stolarski, R. S., A. R. Douglass, S. Steenrod, and S. Pawson, 2006: Trends in stratospheric ozone: Lessons learned from a 3D chemical transport model. J. Atmos. Sci., 63, 10281041.

Telford, P., P. Braesicke, O. Morgenstern, and J. Pyle, 2009: Reassessment of causes of ozone column variability following the eruption of Mount Pinatubo using a nudged CCM. Atmos. Chem. Phys., 9, 4251-4260.

Thomason, L. W., and T. Peter, 2006: The assessment of stratospheric aerosol properties. SPARC Newsletter, No. 26, SPARC, Toronto, ON, Canada, 38-39. [Available online at http://www.atmosp. physics.utoronto.ca/SPARC/Newsletter26.pdf.]

Thompson, D. W. J., and J. M. Wallace, 2000: Annular modes in the extratropical circulation. Part I: Month-to-month variability. J. Climate, 13, 1000-1016.
— and S. Solomon, 2009: Understanding recent stratospheric climate change. J. Climate, 22, 1934-1943.

—, M. P. Baldwin, and S. Solomon, 2005: Stratosphere-troposphere coupling in the Southern Hemisphere. J. Atmos. Sci., 62, 708-715.

Tibaldi, S., E. Tosi, A. Navarra, and L. Pedullli, 1994: Northern and Southern Hemisphere seasonal variability of blocking frequency and predictability. Mon. Wea. Rev., 122, 1971-2003.

Tilmes, S., R. Müller, A. Engel, M. Rex, and J. M. Russell III, 2006: Chemical ozone loss in the Arctic and Antarctic stratosphere between 1992 and 2005. Geophys. Res. Lett., 33, L20812, doi:10.1029/2006GL026925.

Trenberth, K. E., 1980: Planetary waves at $500 \mathrm{mb}$ in the Southern Hemisphere. Mon. Wea. Rev., 108, 1378-1389.

and K. C. Mo, 1985: Blocking in the Southern Hemisphere. Mon. Wea. Rev., 113, 3-21.

Turner, J., 2004: The El Niño-Southern Oscillation and Antarctica. Int. J. Climatol., 24, 1-31.

van Loon, H., and R. L. Jenne, 1972: The zonal harmonic standing waves in the Southern Hemisphere. J. Geophys. Res., 77, $992-$ 1003

Varotsos, C., 2002: The Southern Hemisphere ozone hole split in 2002. Environ. Sci. Pollut. Res., 9, 375-376, doi:10.1007/BF02987584.

Viereck, R. A., L. C. Puga, D. Judge, M. Weber, and W. K. Tobiska, 2001: The Mg II index: A proxy for solar EUV. Geophys. Res. Lett., 28, 1343-1346.

WMO, 2003: Scientific assessment of ozone depletion: 2002. WMO Rep. 47, Global Ozone Research and Monitoring Project, 498 pp. [Available online at http://www.wmo.int/pages/prog/ arep/gaw/ozone_2002/ozone_2002.html.]

, 2007: Scientific assessment of ozone depletion: 2006. WMO Rep. 50, Global Ozone Research and Monitoring Project, 572 pp. [Available online at http://www.wmo.int/pages/prog/arep/ gaw/ozone_2006/ozone_asst_report.html.]

Wohltmann, I., R. Lehmann, M. Rex, D. Brunner, and J. A. Mäder, 2007: A process-oriented regression model for column ozone. J. Geophys. Res., 112, D12304, doi:10.1029/2006JD007573.

Woollings, T., A. Charlton-Perez, S. Ineson, A. G. Marshall, and G. Masato, 2010: Associations between stratospheric variability and tropospheric blocking. J. Geophys. Res., 115, D06108, doi:10.1029/2009JD012742. 